\title{
Annual, seasonal and monthly rainfall trend analysis in the Tafna watershed, Algeria
}

\author{
Afaf Bouklikha ${ }^{1} \cdot$ Mohammed Habi $^{2} \cdot$ Abdelkader Elouissi $^{3} \cdot$ Saaed Hamoudi $^{4}$
}

Received: 5 September 2019 / Accepted: 26 March 2021 / Published online: 15 April 2021

(c) The Author(s) 2021

\begin{abstract}
Scientists, since a long time, have paid attention on climate change and, in particular, rainfall decrease. These changes have resulted in modifications of the rainfall regime in many Mediterranean regions. This work is based on monthly rainfall data from 17 stations located in the Tafna catchment (North West of Algeria). The study aim is to identify long-term (1970-2016) spatial and temporal trends in annual, seasonal and monthly precipitation, using the innovative trend analysis (ITA) method. The approach is used to classify trends into "low", "medium", "high", which should be taken in consideration in future studies on floods ("high") and drought ("low"). The monthly rainfall shows a decreasing trend in all studied stations (100\% of stations) during February, March, April, and May, the same phenomenon observed in the majority of stations for June, July ( $82 \%$ of stations), and December (58\% of stations). Seasonal analysis indicates a downward trend in winter and spring. Using annual rainfall, the stations located in the north, west and central part of the Tafna show a decrease in rainfall (59\% of stations).
\end{abstract}

Keywords Spatiotemporal rainfall variability $\cdot$ Rainfall trend $\cdot$ Climate variability $\cdot$ Tafna watershed (Algeria)

\section{Introduction}

Water resources are of paramount importance and their need in the future increases due to climate and land use changes that can cause rainfall decrease effects in several countries such as Algeria (Elouissi et al. 2016). The United Nations Framework for Climate Change Conservation (UNFCCC) describes climate change as "climate change caused directly or indirectly by human activities that change the composition of the global atmosphere and add to the natural variability of climate observed over comparable time periods" (Mohorji and Sen, 2017; IPCC 2007, 2013). For the majority of Mediterranean regions, these variations have resulted in significant precipitation decreases, with an augmentation of exceptional phenomena such as severe droughts (Ghenim and Megnounif 2016). Algeria, as other Mediterranean countries, will face a decrease in rainfall of around $5-13 \%$ and an increase in temperature of $0.6-1.1^{\circ} \mathrm{C}$ in 2020 (Elmeddahi 2016; Nichane and Khelil 2015). Algeria has suffered over the last 25 years (1975-1998), a severe and persistent drought that has affected the entire territory, and has been particularly severe in the western regions (Taibi et al. 2013). It is classified as a country at risk in the Climate Change Vulnerability Index (Maplecroft 2014). of Hydraulics, Faculty of Civil Engineering and Architecture, Hassiba Benbouali University of Chlef, National Road No 19, Fares, Chlef, Algeria

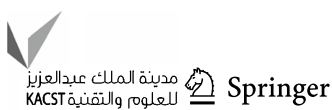




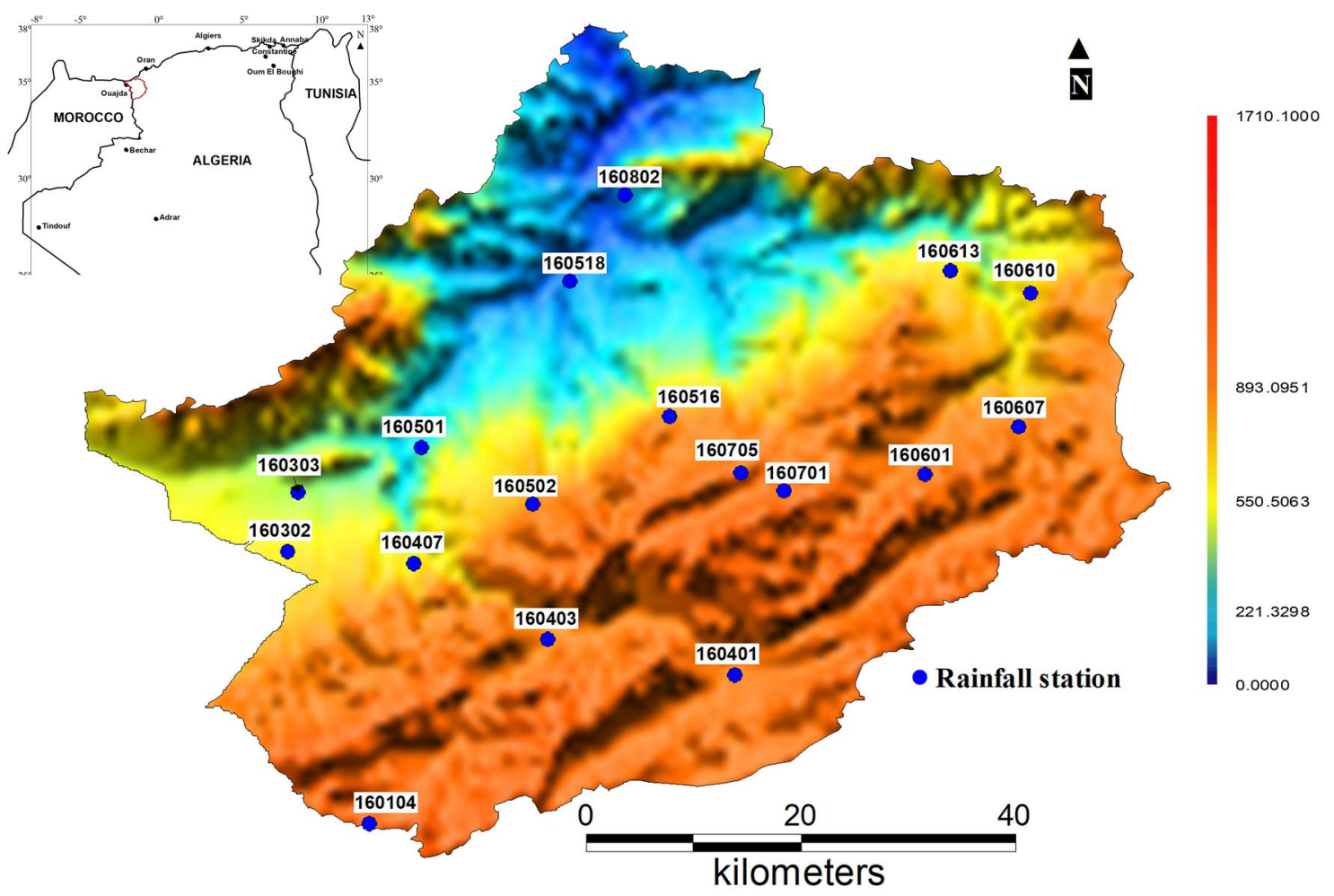

Fig. 1 Tafna watershed and stations locations

Rainfall is a very important factor for climate and hydrometeorology (Sayemuzzaman and Manoj 2013). One can now process numerical data as time series using different methodologies to discover internal systematic structures such as trends, which offer scientific information for more effective modelling, prediction and control of the problem (Mohorji and Sen 2017). Spatiotemporal trends of rainfall results are important to climate analysts and water resource strategists (Sayemuzzaman and Manoj 2013). Like other climatic factors, rainfall time series has often inhomogeneities from different sources. The provision of a long-term, continuous and homogeneous time series for rainfall has important benefits for climate scientists (Mekis and Hogg 1999).

The most significant elements of all rainfall time series are seasonal and systematic variations, but the trend factor requires special attention for its identification (Elouissi et al. 2016; Bouklikha et al. 2020).

Several studies have dealt mostly with droughts on the Mediterranean. They observed a marked increase in the frequency, duration and severity of droughts (Merabti et al. 2017). The interannual variability of annual rainfall is considered to be marked by a significant decrease $(>20 \%)$. It was seen in the second half of the 1970s (Meddi et al. 2010). The average precipitation deficit determined after 1970 is between 23 and 36\%; it is mostly observed during the rainy season (winter and spring) (Ghenim et al. 2010, 2014; Elouissi et al. 2017). After 1975, rainfall decreased by $26 \%$ in Tafna watershed. This decrease translates into a significant reduction in runoff of approximately $62 \%$. The dry years after 1975 are significant at more than 62\% (Meddi et al. 2013).

The purpose of this document is to analyze long-term (1970-2016) spatiotemporal trends of annual, seasonal and monthly rainfall in the Tafna watershed using data from 17 stations.

A new trend method is used. The innovative trend analysis, which is both simple and effective, is offered by Şen (2012). This technique is used to determine the trend by dividing the original series in two halves and comparing between them (Elouissi et al. 2016). The main novelty of this document is to identify the trend of different categories of rainfall based on the approach developed by Şen (2012). The limited access to the data does not allow to study a higher number of stations and a recent period. 


\section{Study area}

The Tafna basin, located at the extreme west of Algeria, between $34^{\circ} 35^{\prime}$ north latitude and $00^{\circ} 32^{\prime}$ west longitude, covers an area of $7245 \mathrm{~km}^{2}$ (Aboura 2006) and is composed of eight sub-basins; The basin is delimited by Tlemcen Mountains, it is mainly composed of mountains in the south (800-1400 m of altitude). This orographic structure, which is dominated to the north by the Taras Mountains (1081 m) of narrow width, constitutes an important barrier against precipitation.

The climate of the Tafna Basin is comparable to that of the entire Mediterranean region of North Africa (Meddi et al. 2013). The general rainfall pattern is comparable to that of the semi-arid Mediterranean regions of northern Algeria (Meddi et al. 2010), with two principal seasons: a long dry warm summer-autumn and a spring-winter with frequent

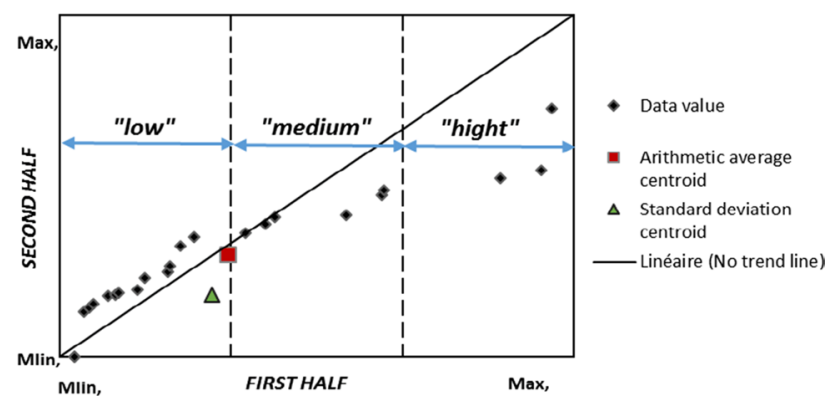

Fig. 2 Innovative trend templates heavy precipitations. The average annual water temperature varies from $11^{\circ} \mathrm{C}$ in winter to $28{ }^{\circ} \mathrm{C}$ in summer (Zettam et al. 2017; Taleb et al. 2008). This system is marked by winter rainfall with peaks in December, January and February, and a long period of dryness from June to September. Annual rainfall varies between 240 and $688 \mathrm{~mm}_{\text {year }}{ }^{-1}$. This system is also marked by high spatial and temporal variability in total rainfall (Meddi et al. 2010).

Monthly rainfall data of 17 stations were collected from ANRH (National Agency for Water Resources) with data length of 17 years (from September 1970 to August 2016) (Fig. 1).

\section{Methodology}

The innovative trend analysis methodology, presented by Şen (2012), is simple and effective, this method has recently been successfully applied in the field of water resources, Şen (2012) indicated that the currently used MK and Spearman rho tests have certain restrictive assumptions, such as independent time series structure, normality of distribution and data length, in contrast to this method. Also, low, medium and high values of a parameter can be evaluated graphically by this method (Kisi and Ay 2013).

In this method, the following steps are performed to obtain a graph that can show possible partial trends for "low", "medium" and "high" precipitation data (Öztopal and Şen 2016). The first phase is to divide a hydrometeorological time series into two equal parts and arrange them in ascending order. The first semi-serial $\left(X_{i}: i=1,2 \ldots n / 2\right)$ is
Table 1 Innovative trend analysis parameters (annual analysis)

\begin{tabular}{|c|c|c|c|c|c|c|c|c|}
\hline \multirow[t]{2}{*}{ Station no } & \multicolumn{2}{|l|}{ 1971-1993 } & \multicolumn{2}{|l|}{ 1994-2016 } & \multirow{2}{*}{$\begin{array}{l}\text { Trend } \\
\text { Slope (-) }\end{array}$} & \multicolumn{3}{|c|}{ Interpretation } \\
\hline & Mean (mm) & $\mathrm{SD}(\mathrm{mm})$ & Mean (mm) & $\mathrm{SD}(\mathrm{mm})$ & & Low & Medium & High \\
\hline 160104 & 245.6 & 135.321798 & 292.3 & 110.139734 & 0.4579248 & + & 0 & + \\
\hline 160302 & 311.9 & 97.5684919 & 277.8 & 69.2950921 & -0.33428295 & 0 & - & - \\
\hline 160303 & 293.0 & 102.028783 & 254.7 & 90.4870717 & -0.37507147 & 0 & - & - \\
\hline 160401 & 421.4 & 118.427108 & 373.3 & 124.342985 & -0.47105588 & 0 & - & - \\
\hline 160403 & 427.2 & 143.631147 & 427.2 & 116.38912 & -0.15 & + & - & - \\
\hline 160407 & 305.9 & 114.725961 & 315.8 & 92.47833282 & 0.09676044 & 0 & 0 & 0 \\
\hline 160501 & 266.6 & 122.723781 & 275.2 & 81.4166896 & 0.0845402 & + & 0 & - \\
\hline 160502 & 406.4 & 103.939648 & 399.4 & 92.9510423 & -0.06830454 & 0 & 0 & 0 \\
\hline 160516 & 424.2 & 112.123438 & 397.9 & 85.1773354 & -0.25789216 & 0 & 0 & - \\
\hline 160601 & 449.6 & 118.405964 & 436.1 & 141.592225 & -0.13248082 & 0 & 0 & + \\
\hline 160610 & 371.7 & 98.1587897 & 358.9 & 107.645179 & -0.12545112 & 0 & - & + \\
\hline 160613 & 389.8 & 100.901592 & 399.9 & 113.384993 & 0.098727 & + & 0 & ++ \\
\hline 160701 & 692.5 & 186.17567 & 601.8 & 202.9639 & -0.88849568 & 0 & - & + \\
\hline 160705 & 586.7 & 160.983678 & 509.5 & 138.56057 & -0.75688746 & 0 & - & 0 \\
\hline 160802 & 337.1 & 110.124 .505 & 330.9 & 90.9697301 & -0.06026901 & + & - & - \\
\hline 160518 & 262.2 & 106.396 .067 & 299.1 & 81.8331278 & 0.36118172 & + & + & - \\
\hline 160607 & 359.7 & 87.0083933 & 358.3 & 106.253766 & -0.01438215 & 0 & - & ++ \\
\hline
\end{tabular}



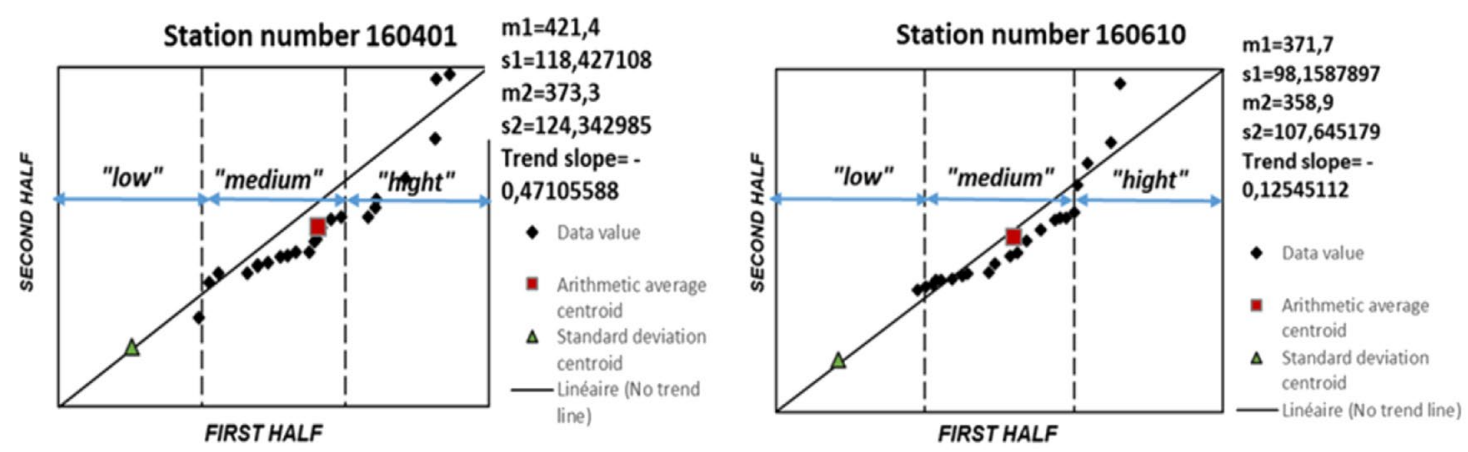

(a) Innovative descending trends
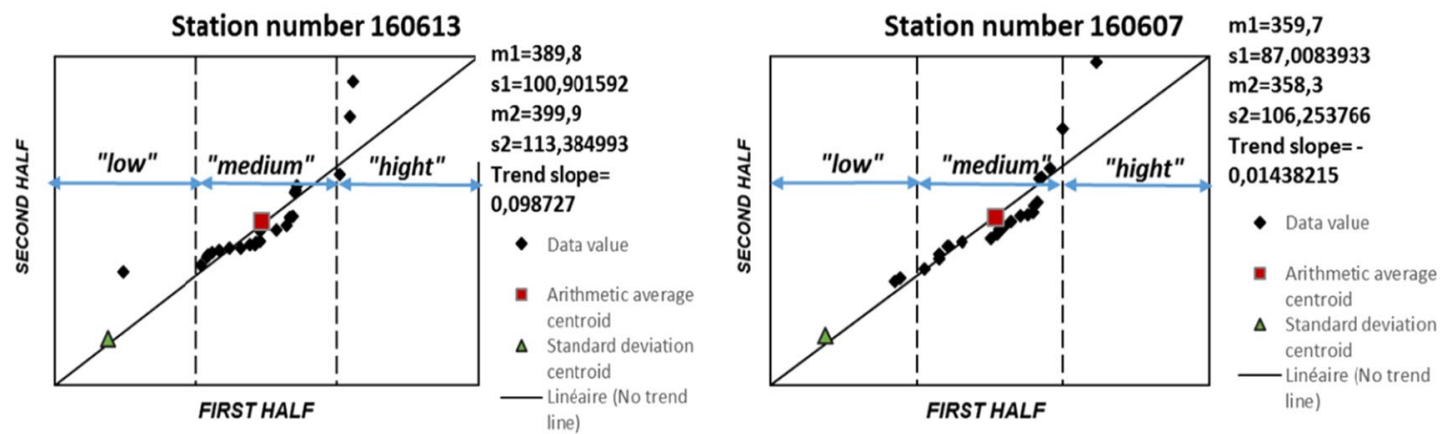

(b) Innovative increasing trends
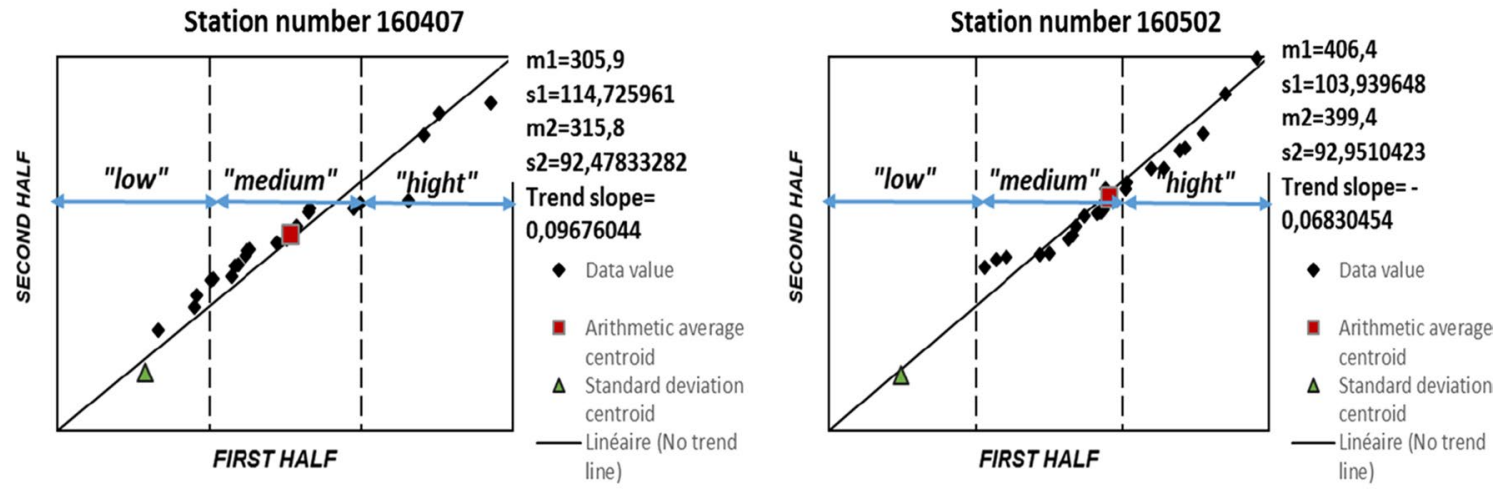

(c) Innovative trends (no trend)

Fig. 3 a Innovative descending trends. b Innovative increasing trends. c Innovative trends (no trend)

placed on the horizontal axis and the second $\left(X_{j}: j=n / 2+1\right.$, $n / 2+2, n / 2+2 \ldots n)$ on the vertical axis to obtain a dispersion diagram. The two axes distance must be the same. The 1:1 straight line $\left(45^{\circ}\right)$ divides the diagram into two equal triangular sections, where the higher (lower) triangular area is for the increasing (decreasing) trend element. If the scattering points appear on or near the 1:1 straight line $\left(45^{\circ}\right)$, this means that there is no significant trend in the hydrometeorological recordings (time series without trend). Else, if the points are above (below) the $1: 1$ straight line $\left(45^{\circ}\right)$, it is possible to confirm an increasing (decreasing) trend in the time series (Dabanli et al. 2016; Şen 2012, 2014). 
Fig. 4 Spatial trend partition of the Tafna watershed area

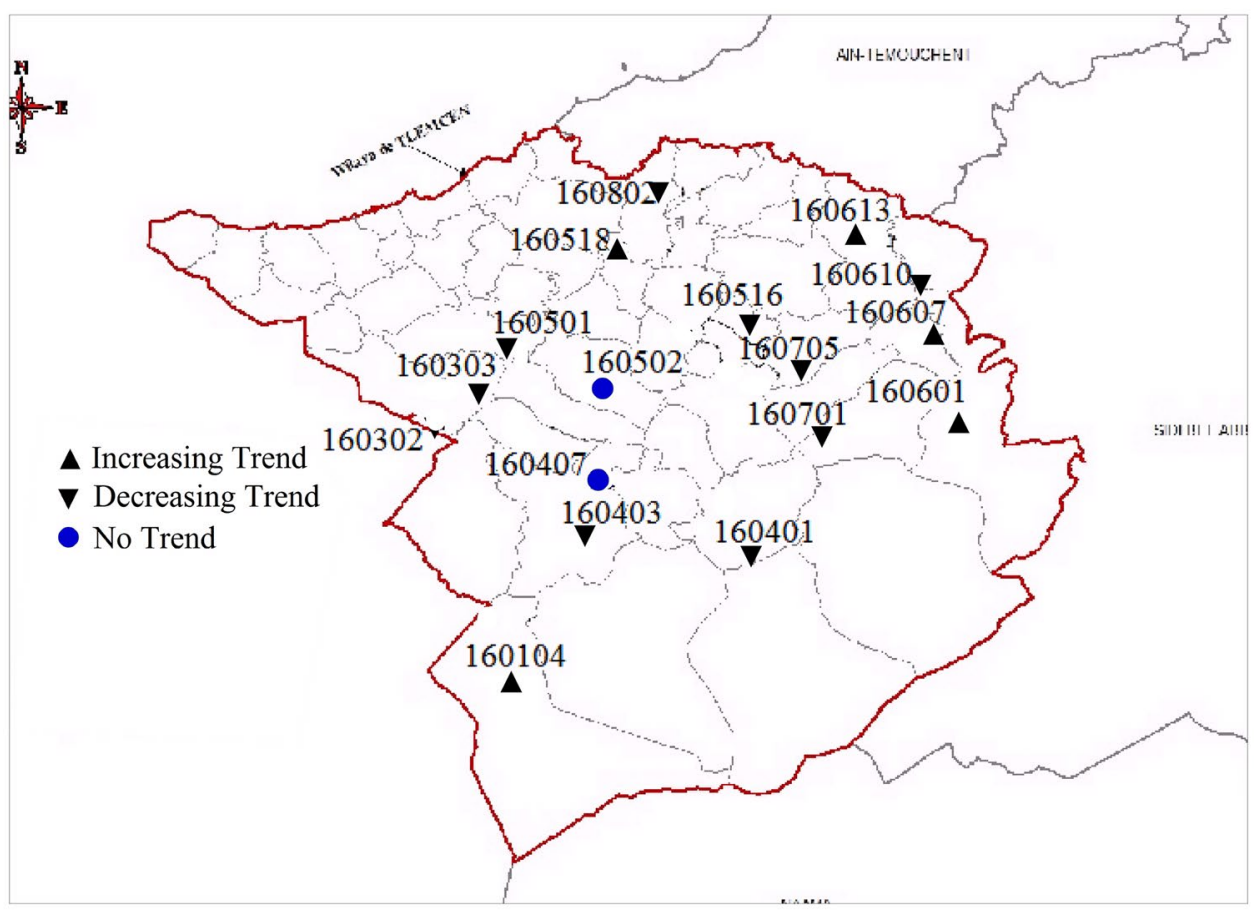

\section{Results and discussion}

Stations with more than $10 \%$ gap were removed. Therefore 17 stations were selected. Outliers detection and filling gaps were applied using Hydrolab Excel Macro (Hydrolab 2010).This software uses the principal component analysis (PCA) (Elouissi et al. 2017).

Monthly values were summed to obtain seasonal and annual precipitation. The seasons were defined as follows: winter (January, February, March); spring (April, May, June); summer (July, August, September) and autumn (October, November, December) (Sayemuzzaman and Manoj 2013).

The application of the innovative trend analysis is presented for 17 weather stations dispersed at different areas of Tafna catchment (Fig. 1). Trend and interception calculations are made using Excel and results are given in figures and tables below.

The arithmetic means ( $m 1$ and $m 2)$, standard deviations ( $s 1$ and $s 2)$ of the half-series (1971-1993 and 1994-2016) and the trend slope $(S)$ are represented in Fig. 2. The latter is calculated using the following expression (Elouissi et al. 2016; Şen 2014):

$S=\frac{(m 2-m 1)}{\left(\frac{n}{2}\right)}$

$n$ is the number of data.

\section{Results}

\section{Annual precipitation trends}

The innovative model offers linguistic interpretation possibilities for the trend. The following steps are performed to obtain a graph that shows possible partial trends,

The largest range of data values is divided into three equal parts,

Each part has three sections ("low", "medium" and "high"), which provide an interpretation domain for each type of group trend,

Each part is compared with the straight line at $45^{\circ}$ (Öztopal and Şen 2016).

The basic characteristics of the stations are presented in Table 1; the last column shows the necessary interpretations, where 0 indicates no significant trend, $+(-)$ indicates a significant increasing (decreasing) trend, $++(-)$ indicates a more important increasing (decreasing) trend than the previous part. Finally $(+++)(---)$ implies a very important increasing (decreasing) trend compared to the two previous parts (Elouissi et al. 2016). Figure $3 \mathrm{a}$ indicates the stations with a decreasing trend, where most of the scatter points are below the 1:1 line. The Stations $(160302,160303$, $160401,160403,160802$ ) show decreases in medium and high precipitation, while stations $(160501,160516)$ show decreases in high precipitation only, there are also decreases in medium precipitation $(160610,160701,160705)$. 
Table 2 Innovative trend analysis parameters (autumn season)

\begin{tabular}{|c|c|c|c|c|c|c|c|c|}
\hline \multirow[t]{2}{*}{ Station no } & \multicolumn{2}{|l|}{ 1971-1993 } & \multicolumn{2}{|l|}{ 1994-2016 } & \multirow{2}{*}{$\begin{array}{l}\text { Trend } \\
\text { Slope (-) }\end{array}$} & \multicolumn{3}{|c|}{ Interpretation } \\
\hline & Mean (mm) & $\mathrm{SD}(\mathrm{mm})$ & Mean (mm) & $\mathrm{SD}(\mathrm{mm})$ & & Low & Medium & High \\
\hline 160104 & 67.3 & 39.664933 & 105.8 & 62.6535507 & 0.37769239 & + & ++ & + \\
\hline 160302 & 90.6 & 57.4924776 & 101.0 & 54.9188237 & 0.10186804 & + & + & 0 \\
\hline 160303 & 86.3 & 51.4854759 & 100.0 & 63.3554887 & 0.13466657 & 0 & + & + \\
\hline 160401 & 126.9 & 54.9472811 & 119.1 & 54.4915365 & -0.07671489 & 0 & 0 & 0 \\
\hline 160403 & 128.7 & 68.3368844 & 145.9 & 81.9361821 & 0.169394741 & 0 & + & + \\
\hline 160407 & 89.0 & 56.3325323 & 108.8 & 63.8378609 & 0.19339301 & + & ++ & + \\
\hline 160501 & 74.4 & 49.8852759 & 102.2 & 61.7611263 & 0.27196561 & + & + & ++ \\
\hline 160502 & 117.0 & 63.3022585 & 140.1 & 74.89062001 & 0.22642708 & 0 & + & + \\
\hline 160516 & 118.7 & 57.9783483 & 142.0 & 62.8386912 & 0.22855636 & 0 & + & 0 \\
\hline 160601 & 132.1 & 57.3237612 & 143.7 & 69.0570215 & 0.11364024 & 0 & + & ++ \\
\hline 160610 & 112.2 & 52.758606 & 124.9 & 61.0936416 & 0.12443467 & 0 & 0 & ++ \\
\hline 160613 & 124.8 & 59.1994387 & 144.4 & 69.1350044 & 0.19181711 & 0 & + & ++ \\
\hline 160701 & 206.3 & 83.1252803 & 219.8 & 122.95152 & 0.12188427 & 0 & + & 0 \\
\hline 160705 & 172.5 & 74.840355 & 179.3 & 90.5308809 & 0.06670929 & 0 & 0 & 0 \\
\hline 160802 & 109.2 & 54.2016849 & 132.0 & 66.9807709 & 0.2237517 & 0 & + & + \\
\hline 160518 & 83.7 & 57.1473159 & 110.2 & 63.1540816 & 0.25977158 & + & + & 0 \\
\hline 160607 & 104.1 & 47.4642513 & 125.9 & 63.8780477 & 0.21352223 & + & + & ++ \\
\hline
\end{tabular}
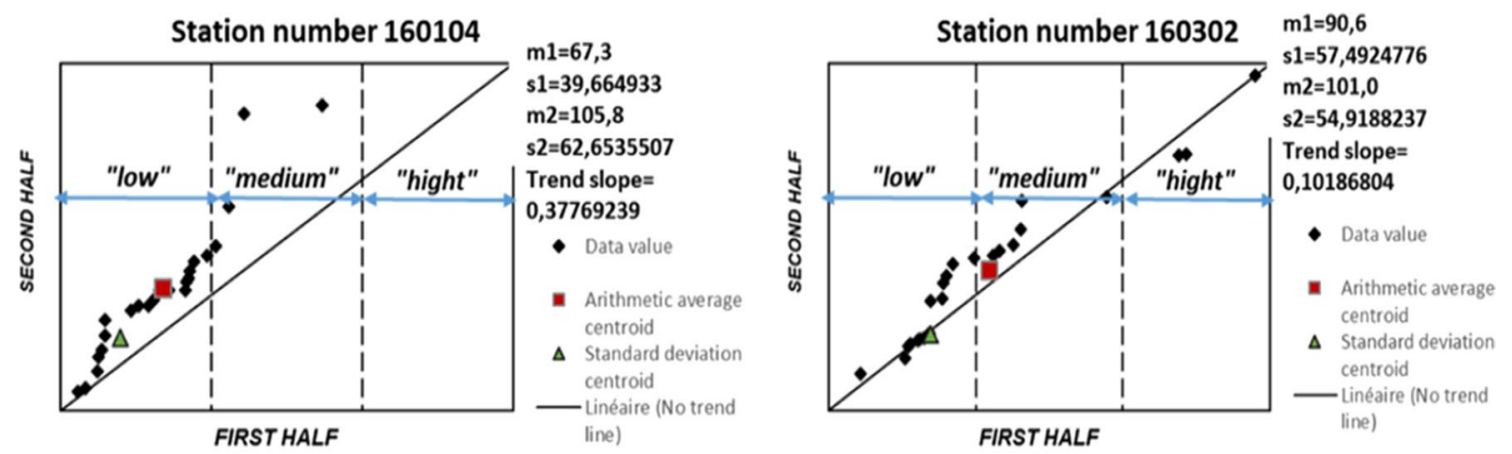

(a) Innovative increasing trends
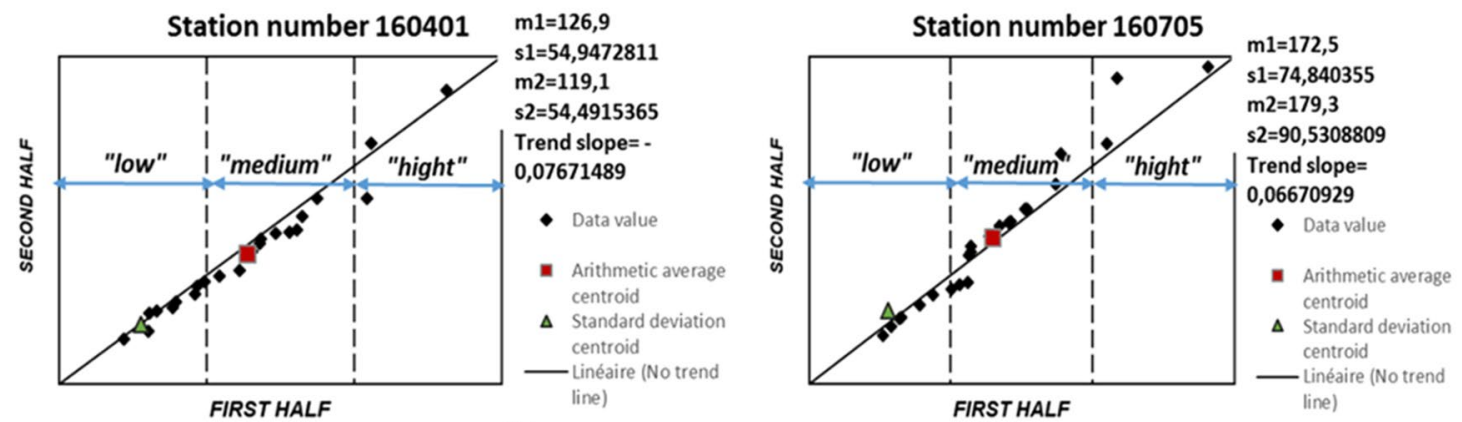

(b) Innovative trends (no trend)

Fig. 5 a Innovative increasing trends. b Innovative trends (no trend) 
Fig. 6 Spatial trend partition of the Tafna watershed area (autumn season)

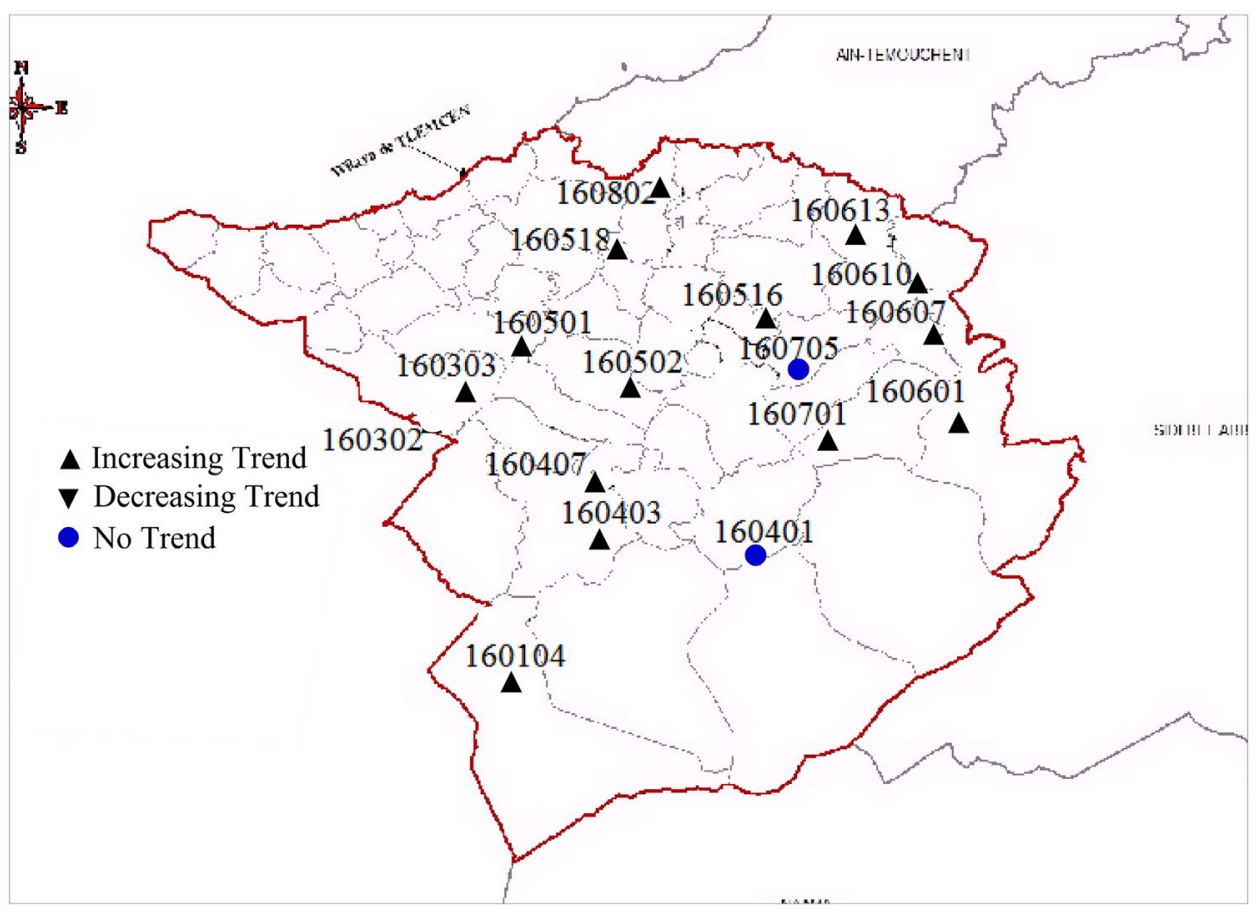

Figure $3 \mathrm{~b}$ represents stations with increasing trends; the stations $(160104,160613)$ have increasing trends in low and high precipitation. Some stations display increases in high precipitation only with decreasing trends in medium precipitation $(160601,160607)$, while there are stations showing increases in low and medium precipitation and decreases in high precipitation (160518).

Finally, Fig. 3c shows no trend stations; the scatter points are on/or near to the line (1.1) $(160407,160502)$.

Analysis of the annual precipitation time series found that $59 \%$ of stations has a decreasing trend $(160302$, 160303, 160401, 160403, 160802, 160501, 160516, $160610,160701,160705)$; they are mainly found in the north, west and middle part of the Tafna catchment (Fig. 4). One can also find stations with decreases but a slight increase for the low values.

The stations with an increasing trend present $29 \%$ of the stations, the majority are located in the eastern part of the basin, (160104, 160613, 160601, 160607, 160518), and most of its stations show a decrease in medium precipitation. Meddi et al. (2013) found a similar result on annual rainfall.

\section{Seasonal precipitation trends}

For each station, we have calculated the cumulative rainfall for a season.

\section{Autumn}

As can be seen in Table 2 the interpretations for the autumn season, a very large number $(88 \%)$ of stations were found with increasing trends $(160104,160302,160303,160403$, $160407,160501,160502,160516,160601,160613,160610$, $160701,160802,160518,160607)$ as shown in Fig. 5a. Several stations show important significant increasing trends $(++)$ at high precipitation values $(160501,160601,160610$, $160613,160607)$, the stations $(160407,160104)$ have important significant increasing trends $(++)$ in medium precipitation, while others have an increasing trend $(+)$ in low and medium precipitation values, we can also find increases in medium precipitation only. Figure $5 \mathrm{~b}$ doesn't show a clear trend (no trend) $(160401,160705)$. No decreasing trend was marked as shown on the map in Fig. 6.

\section{Winter}

The winter season represents a decrease in rainfall in the majority of stations, 14 of 17 (82\%) (Table 3). The stations (160303, 160403, 160407, 160701, 160705, 160401) indicated important significant decreasing trends (-) in high precipitation, and decreasing trends $(-)$ in medium and low precipitation, while the stations $(160104,160302,160501$, $160502,160516,160601,160613$ ) have decreasing trends (-) in high precipitation only. The station (160610) has 
Table 3 Innovative trend analysis parameters (winter season)

\begin{tabular}{|c|c|c|c|c|c|c|c|c|}
\hline \multirow[t]{2}{*}{ Station no } & \multicolumn{2}{|l|}{ 1971-1993 } & \multicolumn{2}{|l|}{ 1994-2016 } & \multirow{2}{*}{$\begin{array}{l}\text { Trend } \\
\text { Slope (-) }\end{array}$} & \multicolumn{3}{|c|}{ Interpretation } \\
\hline & Mean (mm) & $\mathrm{SD}(\mathrm{mm})$ & Mean $(\mathrm{mm})$ & $\mathrm{SD}(\mathrm{mm})$ & & Low & Medium & High \\
\hline 160104 & 96.6 & 70.2230342 & 100.4 & 53.093895 & 0.03793417 & + & 0 & - \\
\hline 160302 & 113.9 & 60.523756 & 105.4 & 48.708925 & -0.0833044 & 0 & 0 & - \\
\hline 160303 & 116.5 & 62.1867031 & 93.1 & 46.4718727 & 0.22941913 & - & - & - \\
\hline 160401 & 175.2 & 83.9771027 & 138.2 & 79.2295417 & -0.36311834 & - & - & - \\
\hline 160403 & 198.0 & 105.754435 & 158.5 & 78.3796232 & -0.38682864 & 0 & - & - \\
\hline 160407 & 124.5 & 72.404158 & 119.0 & 62.05831 & -0.05353794 & 0 & 0 & - \\
\hline 160501 & 111.7 & 71.2394393 & 102.7 & 50.6864273 & -0.08815004 & 0 & 0 & - \\
\hline 160502 & 166.5 & 87.1417425 & 155.1 & 79.0479715 & -0.11182455 & 0 & 0 & - \\
\hline 160516 & 175.9 & 81.0416791 & 148.9 & 71.7365183 & -0.26538348 & 0 & 0 & - \\
\hline 160601 & 188.7 & 87.9675657 & 160.8 & 71.3766315 & -0.27352941 & 0 & 0 & - \\
\hline 160610 & 158.7 & 67.7341568 & 141.4 & 67.7932469 & -0.16921433 & 0 & - & - \\
\hline 160613 & 156.8 & 66.7911798 & 158.1 & 72.5924736 & 0.01262122 & 0 & 0 & - \\
\hline 160701 & 304.8 & 145.363524 & 225.9 & 120.353012 & -0.77313428 & - & - & - \\
\hline 160705 & 237.0 & 125.712506 & 192.3 & 92.3850569 & -0.43853367 & 0 & - & - \\
\hline 160802 & 138.1 & 57.7822921 & 130.2 & 61.0378392 & -0.07766947 & 0 & 0 & 0 \\
\hline 160518 & 111.0 & 48.9415152 & 123.1 & 59.6132351 & 0.11565541 & 0 & + & + \\
\hline 160607 & 143.9 & 64.6555956 & 131.1 & 66.8035246 & -0.12527702 & 0 & 0 & 0 \\
\hline
\end{tabular}

decreasing trends $(-)$ in medium and high precipitation (Fig. 7a).

Only one station showed increasing trends in medium and high precipitation (160518) as found in Fig. 7b. For stations (160802, 160607) no trend was marked (Fig. 7c). The map in Fig. 8 reveals that decreasing trend affect almost all station.

\section{Spring}

The interpretation made for the spring season shows a behavior similar to the winter (Table 4); the only particularity is that the decreasing trend affects all the stations in the watershed as depicted in Figs. 9 and 10.

The majority of stations showed important significant decreasing trends (-) in high precipitation and significant decreasing trends (-) in medium precipitation (160104, 160403, 160407, 160502, 160516, 160701, $160705,160802,160607)$ as represented in Table 4 , while the stations $(160302,160303,160401,160501)$ showed important significant decreasing trends $(-)$ in medium and high precipitation, some stations showed decreases (-) in medium and high precipitation.

\section{Summer}

The summer season is marked by an increase in rainfall in $82 \%$ of the stations (Table 5); seven stations show important significant increases (++) (160104, 160303, 160403, 160407, 160502, 160516, 160607) (Fig. 11a). However, the stations $(160401,160501)$ show increasing precipitation (+) in low, medium and high values, there may also be increases $(+)$ in low, medium, or high precipitation only (160302, 160601, 160610, 160613, 160701).

In Fig. 11b, $17 \%$ of the stations have significant decreases in high precipitation $(160705,160802,160518)$ located in the north of the Tafna catchment area mapped in Fig. 12.

\section{Monthly precipitation trends}

\section{September month}

The September month results are illustrated in Fig. 13. With increasing trends in the majority of stations, the affected stations are $(160104,160302,160303,160401,160407$, 160501, 160502, 160516, 161601, 160610, 160613, 160701, $160705,160607)$, while the stations $(160403,160802$, 160518) have decreasing trends.

\section{October month}

Most stations in Fig. 14 have increasing trends; the stations concerned are $(160104,160401,160403,160407$, 160501, 160502, 160516, 160601, 160610, 160613, 160705, $160802,160607)$. We notice decreasing trends in the stations (160302, 160303, 160701, 160518).

\section{November month}

November is also marked by an increase in rainfall (Fig. 15), the stations $(160104,160302,160302,160303,160407$, 160501, 160516, 161601, 160610, 160613, 160802, 160518, 160607) have increasing trends; however, three stations have 

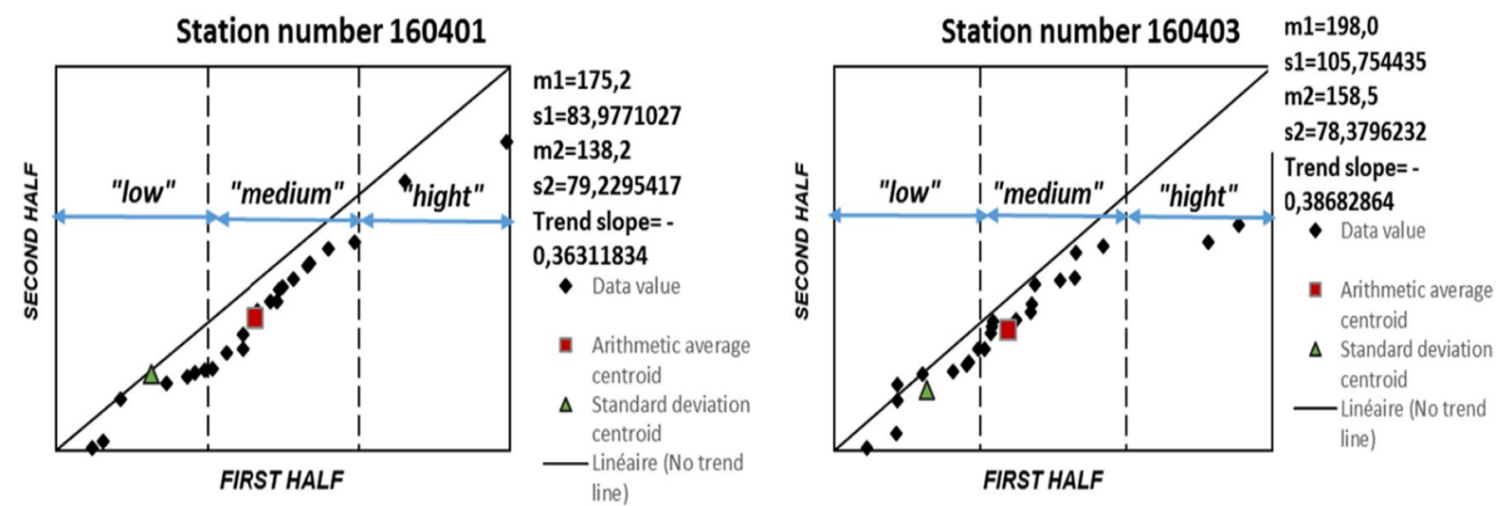

(a) Innovative descending trends

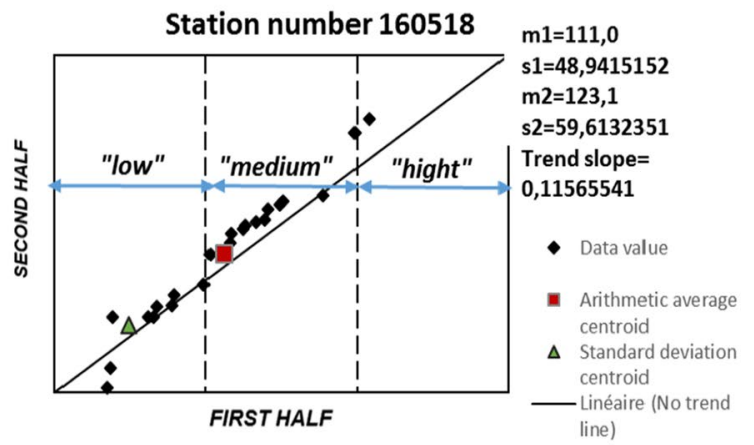

(b) Innovative increasing trends
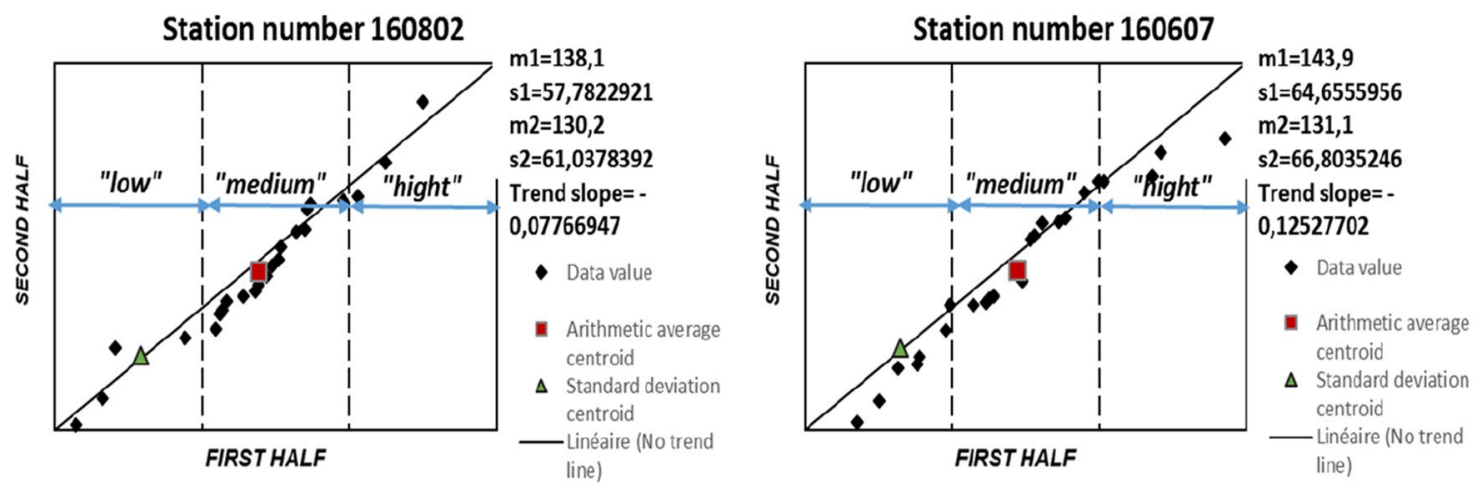

(c) Innovative trends (no trend)

Fig. 7 a Innovative descending trends. b Innovative increasing trends. c Innovative trends (no trend)

decreasing trends $(160401,160502,160701)$. The station 160705 shows no trend.

\section{December month}

In Fig. 16, ten stations show a decrease in rainfall. These are $(160302,160303,160401,160403,160407,160501$, $160502,160516,160705,160518)$, and an increase in rainfall for seven stations $(160104,160601,160610,160613$, 160701, 160802, 160607).

\section{January month}

January month indicates an increase in rainfall in all stations as represented in Fig. 17

\section{February month}

The month of February, in contrast to January, has the aspect of a decreasing trend for all stations (Fig. 18), except the station (160518), which made the exception by an increase in rainfall. 
Fig. 8 Spatial trend partition of the Tafna watershed area (winter season)

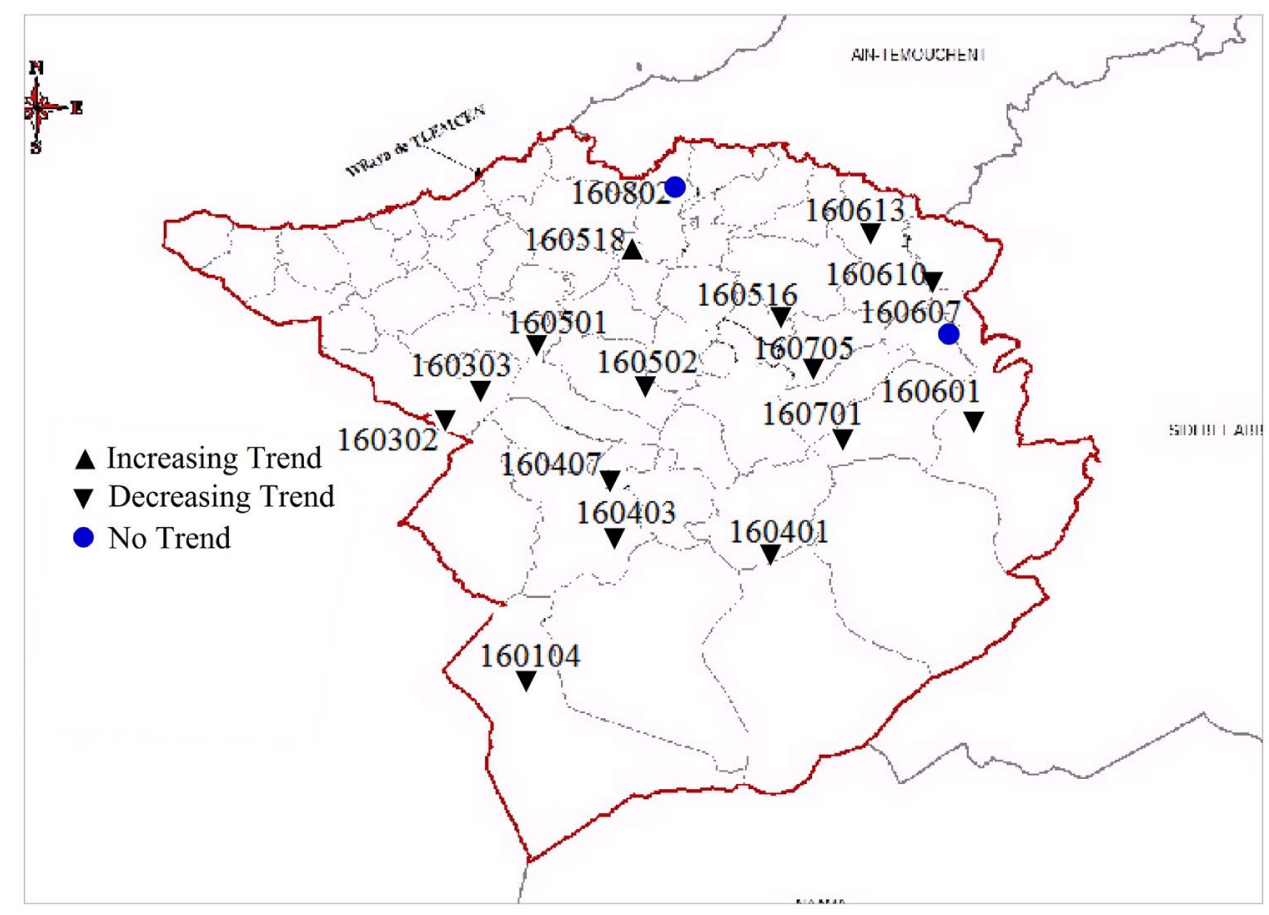

\section{March month}

March (Fig. 19) gives almost the same results as February, with a decreasing in rainfall in all stations of Tafna watershed.

\section{April month}

All stations in April month showed a decrease in rainfall (Fig. 20) except the station 160601, which did not represent any trend.

\section{May month}

This month also represents a decrease in rainfall for all stations (Fig. 21).

\section{June month}

The month of June is marked by a decrease in rainfall in most stations (Fig. 22) (160104, 160302, 160303, 160401, 160501, 160501, 160502, 160516, 160610, 160613, 160701, $160705,160802,160518,160607)$; however, the stations $(160403,160601)$ made the exception by an increase in rainfall. The station (160407) has no trend.

\section{July month}

July month shows a decrease in rainfall, almost the same result as June (Fig. 23) (160104, 160302, 160303, 160401,
160403, 160502, 160516, 160601, 160610, 160613, 160701, $160705,160802,160518)$. The stations $(160407,160501)$ have an increase in rainfall, and no trend was observed for the station (160607).

\section{August month}

This month has a remarkable increase trend in most stations (Fig. 24) (160104, 160302, 160401, 160403, 160407, 160502, 160516, 160610, 160613, 160705, 160802, 160518, $160607)$, and a decrease in rainfall for the stations (160303, 160501, 160601, 160701).

\section{Discussion}

Annual precipitation shows decreasing trend in 59\% of stations, in these graphs, the arithmetic average and standard deviation centroids are below the no-trend line, which indicates a downward trend. In contrast, the arithmetic average and standard deviation of the increasing trends are above the zero trend line.

It is evident that in case of high precipitation the trend is more effective, because the points of high precipitation are further from the straight line 1.1, in comparison with precipitation values "'low', ' medium'. This case is valid for stations (160613, 160601, 160607).

For information, six of the ten stations of the decreasing trend have an altitude of less than $600 \mathrm{~m}$, the principal reason, in our opinion, is that the impact of climate change 
Table 4 Innovative trend analysis parameters (spring season)

\begin{tabular}{|c|c|c|c|c|c|c|c|c|}
\hline \multirow[t]{2}{*}{ Station no } & \multicolumn{2}{|l|}{ 1971-1993 } & \multicolumn{2}{|l|}{ 1994-2016 } & \multirow{2}{*}{$\begin{array}{l}\text { Trend } \\
\text { Slope (-) }\end{array}$} & \multicolumn{3}{|c|}{ Interpretation } \\
\hline & Mean (mm) & $\mathrm{SD}(\mathrm{mm})$ & Mean (mm) & $\mathrm{SD}(\mathrm{mm})$ & & Low & Medium & High \\
\hline 160104 & 63.1 & 56.7399442 & 55.1 & 39.6160464 & -0.07809929 & 0 & - & - \\
\hline 160302 & 90.2 & 59.5328966 & 50.1 & 31.1374842 & -0.39247193 & - & - & - \\
\hline 160303 & 78.6 & 55.1134195 & 41.2 & 27.7615593 & -0.36720372 & - & - & - \\
\hline 160401 & 94.8 & 59.2321566 & 73.5 & 53.5989706 & -0.20950759 & - & - & - \\
\hline 160403 & 96.1 & 74.2107684 & 83.6 & 52.338947 & -0.12225264 & 0 & - & - \\
\hline 160407 & 81.5 & 69.7486243 & 62.1 & 42.7413288 & -0.19015345 & 0 & - & - \\
\hline 160501 & 67.7 & 67.3933146 & 49.1 & 31.9608029 & -0.18299233 & 0 & - & - \\
\hline 160502 & 109.2 & 87.0469034 & 75.7 & 47.2650457 & -0.32804774 & 0 & - & - \\
\hline 160516 & 108.9 & 85.7450265 & 76.8 & 48.2446503 & -0.31508069 & 0 & - & - \\
\hline 160601 & 104.1 & 62.6133915 & 96.9 & 85.4162908 & -0.07063086 & 0 & - & + \\
\hline 160610 & 81.9 & 48.8190201 & 66.1 & 40.3659315 & -0.15528246 & - & - & - \\
\hline 160613 & 84.2 & 53.6710584 & 71.2 & 40.7200633 & -0.12774068 & 0 & - & - \\
\hline 160701 & 153.7 & 109.718762 & 122.1 & 72.7281165 & -0.31033178 & 0 & - & - \\
\hline 160705 & 149.6 & 94.3718547 & 104.9 & 60.2222487 & -0.43844585 & 0 & - & - \\
\hline 160802 & 74.7 & 45.6000052 & 49.8 & 31.5675385 & -0.24416027 & - & - & - \\
\hline 160518 & 51.7 & 38.265056 & 47.4 & 32.5861188 & -0.04222067 & 0 & - & - \\
\hline 160607 & 904 & 53.8172687 & 66.3 & 34.0035638 & -0.23581754 & 0 & - & - \\
\hline
\end{tabular}

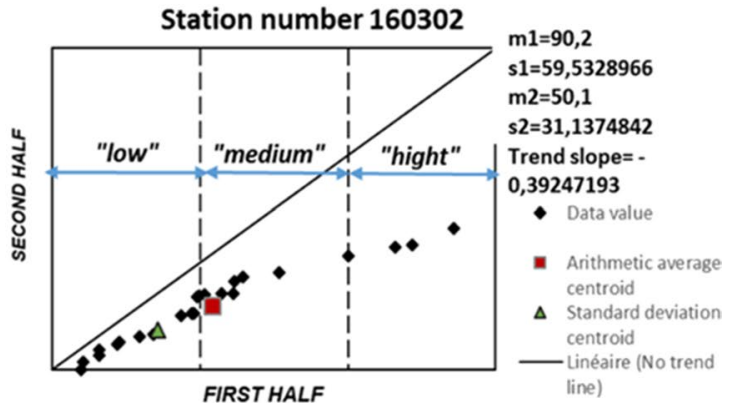

Fig. 9 Innovative descending trends

is apparently hard in low altitude areas than in the high altitude areas.

Similar results are found in different studies. EstebanParra et al. (1998) showed a long-term annual decrease in rainfall for the Mediterranean coast and inland. Meddi et al. (2013) reported a reduction in rainfall of $20-30 \%$ in north Algeria. Many other studies have also highlighted this phenomenon in North Africa in particular and in the Mediterranean in general (Longobardi and Vallani 2001; LópezMoreno et al. 2010; Goubanova and Li 2007; Meddi et al. 2010).

At the seasonal scale, the results showed a decreasing trend at almost all stations in winter and spring. The Mediterranean oscillation (MO) and the North Atlantic Oscillation (NOA) have an impact on precipitation in the western regions because they are closer to the Atlantic, especially rainfall in wet periods in winter.

Several studies have found that the MO and NAO indices influence the seasonal variability of precipitation in the Mediterranean basin, particularly in winter (Lopez-Bustins 2007; Salameh 2008; López-Moreno et al. 2010; Meddi 2009; Taibi et al. 2014). Results of this paper are in line with others, Goubanova and Li (2007) and Toggweiler and Key (2001) have also observed that rainfall intensity will be decreased mainly from February to May, using downscaling statistics.

Monthly rainfall study is marked by seven months with decreasing trend: February, March, April, May (100\% of stations). June, July ( $82 \%$ of stations). December (58\% of stations) (Goubanova and Li 2007; Toggweiler and Key 2001). 
Fig. 10 Spatial trend partition of the Tafna watershed area (spring season)

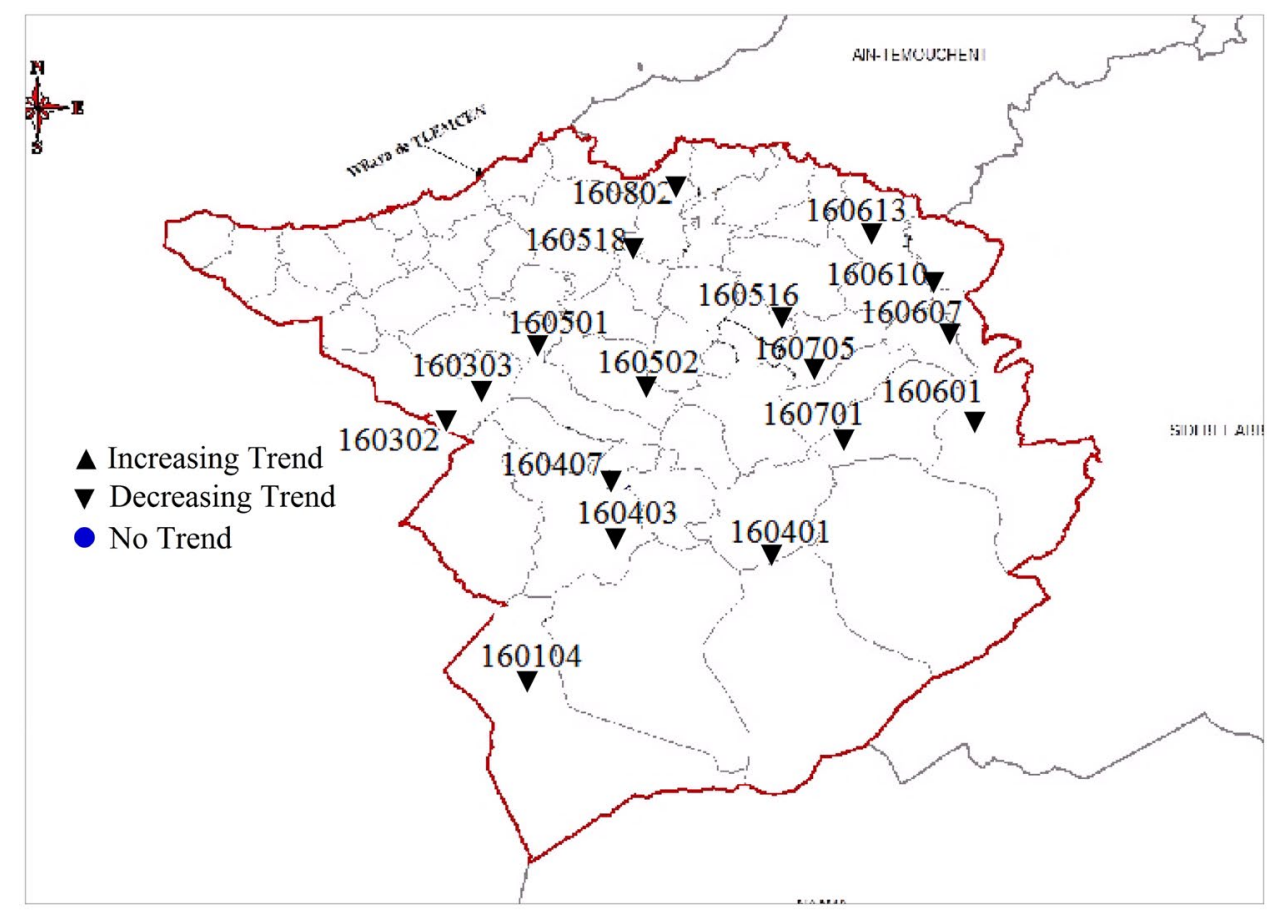

In general, it is clear that the monthly rainfall in northwest Algeria is also influenced by the Mediterranean Oscillation (MO) and the North Atlantic Oscillation (NAO) (Taibi et al. 2014).

\section{Conclusion}

The innovative trend analysis applied to the 17 stations of Tafna catchment (western Algeria) is one of the fundamental ways to identify the impacts of climate change on hydro-meteorological data. Climate change in the study area has a negative impact on the rainfall cycle, including the entire water resource. The reduction in precipitation clearly produces in annual rainfall study witch showed decreasing trend in $59 \%$ of stations, mainly located in the north, middle and west part the catchment. Increasing trend is established in eastern part and affects $29 \%$ of studied stations. The seasonal study showed decreasing trend in almost all stations in winter and spring seasons. However, autumn and summer seasons showed an increasing trend in the majority of stations. Finally, monthly trend analysis indicates a decrease in all studied stations in February, March, April, and May; these are the months most affected by climate change. We noticed the same phenomenon for June and July ( $82 \%$ of stations), and December (58\% of stations). January was characterized by an increase in all stations (100\%). September, October, November and August have a lower increasing trend than January, with a respective stations percent $(82 \%, 76 \%, 76 \%, 76 \%, 82 \%)$.

The consequences of these water shortages are changes in the environmental balance, which will therefore affect various human activities, in particular the supply of water availability for domestic and industrial consumption as well as for the agricultural economy. 
Table 5 Innovative trend analysis parameters (summer season)

\begin{tabular}{|c|c|c|c|c|c|c|c|c|}
\hline \multirow[t]{2}{*}{ Station no } & \multicolumn{2}{|l|}{ 1971-1993 } & \multicolumn{2}{|l|}{ 1994-2016 } & \multirow{2}{*}{$\begin{array}{l}\text { Trend } \\
\text { Slope (-) }\end{array}$} & \multicolumn{3}{|c|}{ Interpretation } \\
\hline & Mean (mm) & $\mathrm{SD}(\mathrm{mm})$ & Mean (mm) & $\mathrm{SD}(\mathrm{mm})$ & & Low & Medium & High \\
\hline 160104 & 18.7 & 18.7662165 & 31.0 & 20.2391604 & 0.12039752 & + & + & ++ \\
\hline 160302 & 17.3 & 13.6007166 & 21.3 & 21.4436263 & 0.03962535 & 0 & + & + \\
\hline 160303 & 11.5 & 12.4914453 & 20.4 & 27.2134012 & 0.0868848 & + & ++ & + \\
\hline 160401 & 24.4 & 19.1637736 & 42.6 & 22.0918716 & 0.17828495 & + & + & + \\
\hline 160403 & 19.8 & 12.9170369 & 39.1 & 24.285096 & 0.18968457 & + & ++ & + \\
\hline 160407 & 10.9 & 11.1551172 & 25.9 & 20.9894628 & 0.14705882 & ++ & ++ & + \\
\hline 160501 & 12.7 & 14.3273833 & 21.3 & 19.7573432 & 0.08371697 & + & + & + \\
\hline 160502 & 13.7 & 12.0385481 & 28.5 & 18.8349446 & 0.14514066 & + & ++ & + \\
\hline 160516 & 20.7 & 14.140213 & 30.2 & 23.3223815 & 0.09401566 & 0 & ++ & + \\
\hline 160601 & 24.7 & 23.6998357 & 34.7 & 28.3123718 & 0.09803922 & + & 0 & + \\
\hline 160610 & 18.9 & 21.1973204 & 26.5 & 19.7234483 & 0.074611 & + & + & 0 \\
\hline 160613 & 24.0 & 18.8698854 & 26.2 & 23.49154 & 0.02202935 & 0 & + & + \\
\hline 160701 & 27.7 & 28.0798508 & 34.1 & 21.8086704 & 0.0630861 & + & 0 & 0 \\
\hline 160705 & 27.6 & 23.7561592 & 33.1 & 20.1285346 & 0.05338277 & + & - & - \\
\hline 160802 & 15.1 & 23.3785821 & 18.9 & 16.7317301 & 0.03780904 & + & + & - \\
\hline 160518 & 15.8 & 21.8093841 & 18.3 & 14.9519322 & 0.0249754 & + & 0 & - \\
\hline 160607 & 21.3 & 16.5703788 & 34.9 & 26.8047488 & 0.13319018 & + & ++ & + \\
\hline
\end{tabular}
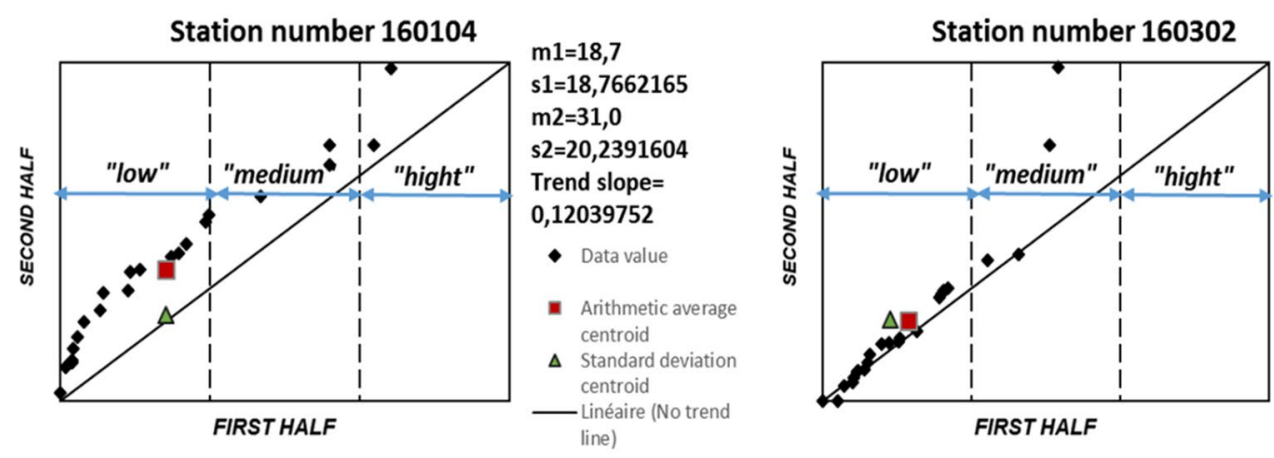

$\mathrm{m} 1=17,3$

$s 1=13,6007166$

$\mathrm{m} 2=21,3$

$s 2=21,4436263$

Trend slope $=$

0,03962535

- Data value

- Arithmetic average centroid

$\Delta$ Standard deviation centroid

- Linéaire (No trend line

(a) Innovative increasing trends
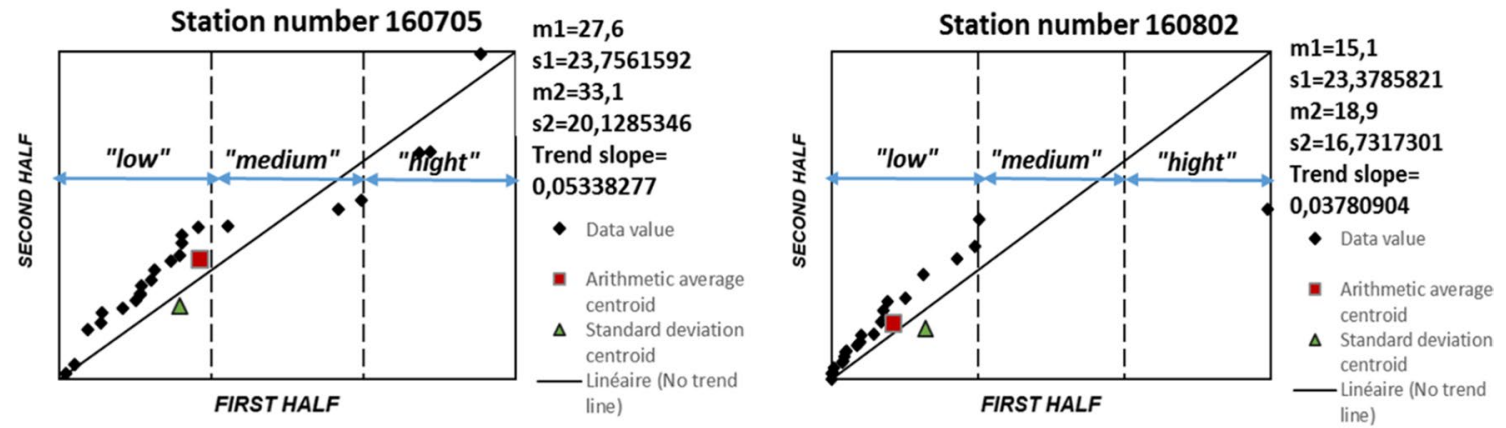

(b) Innovative descending trends

Fig. 11 a Innovative increasing trends. b Innovative descending trends 
Fig. 12 Spatial trend partition of the Tafna watershed area (spring season)
Fig. 13 Spatial trend partition of the Tafna watershed area (September month)
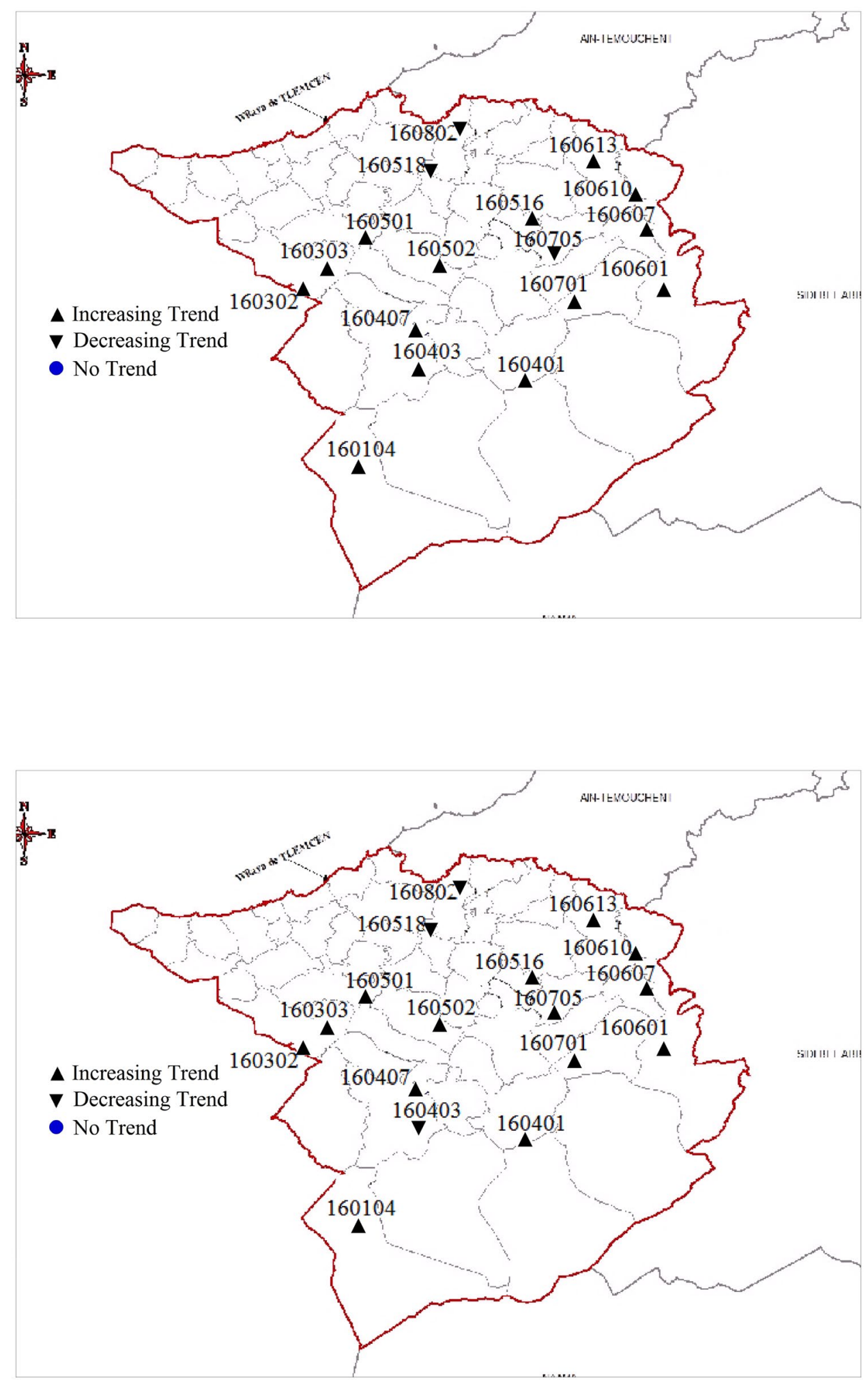
Fig. 14 Spatial trend partition of the Tafna watershed area (October month)
Fig. 15 Spatial trend partition of the Tafna watershed area (November month)
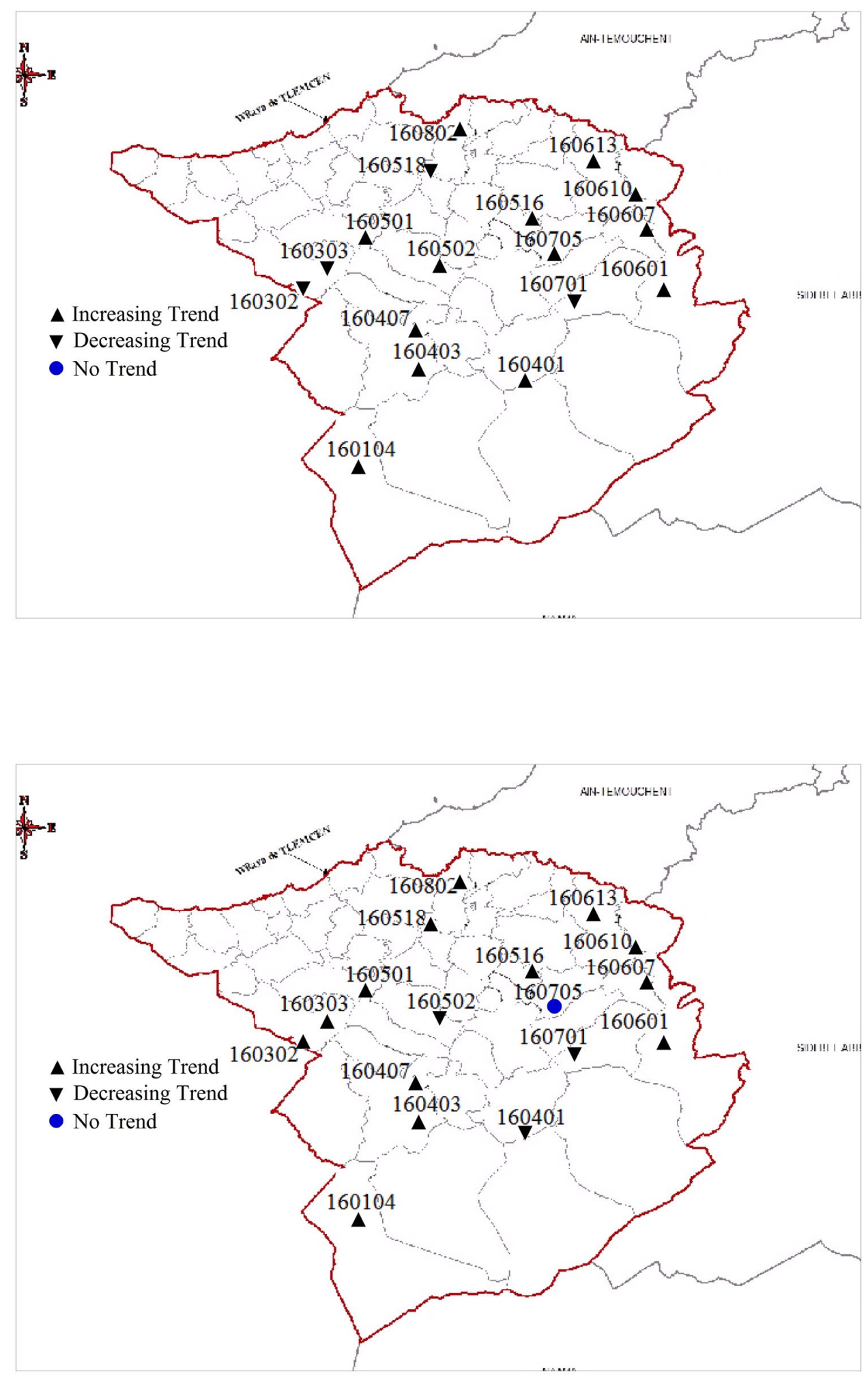
Fig. 16 Spatial trend partition of the Tafna watershed area (December month)
Fig. 17 Spatial trend partition of the Tafna watershed area (January month)
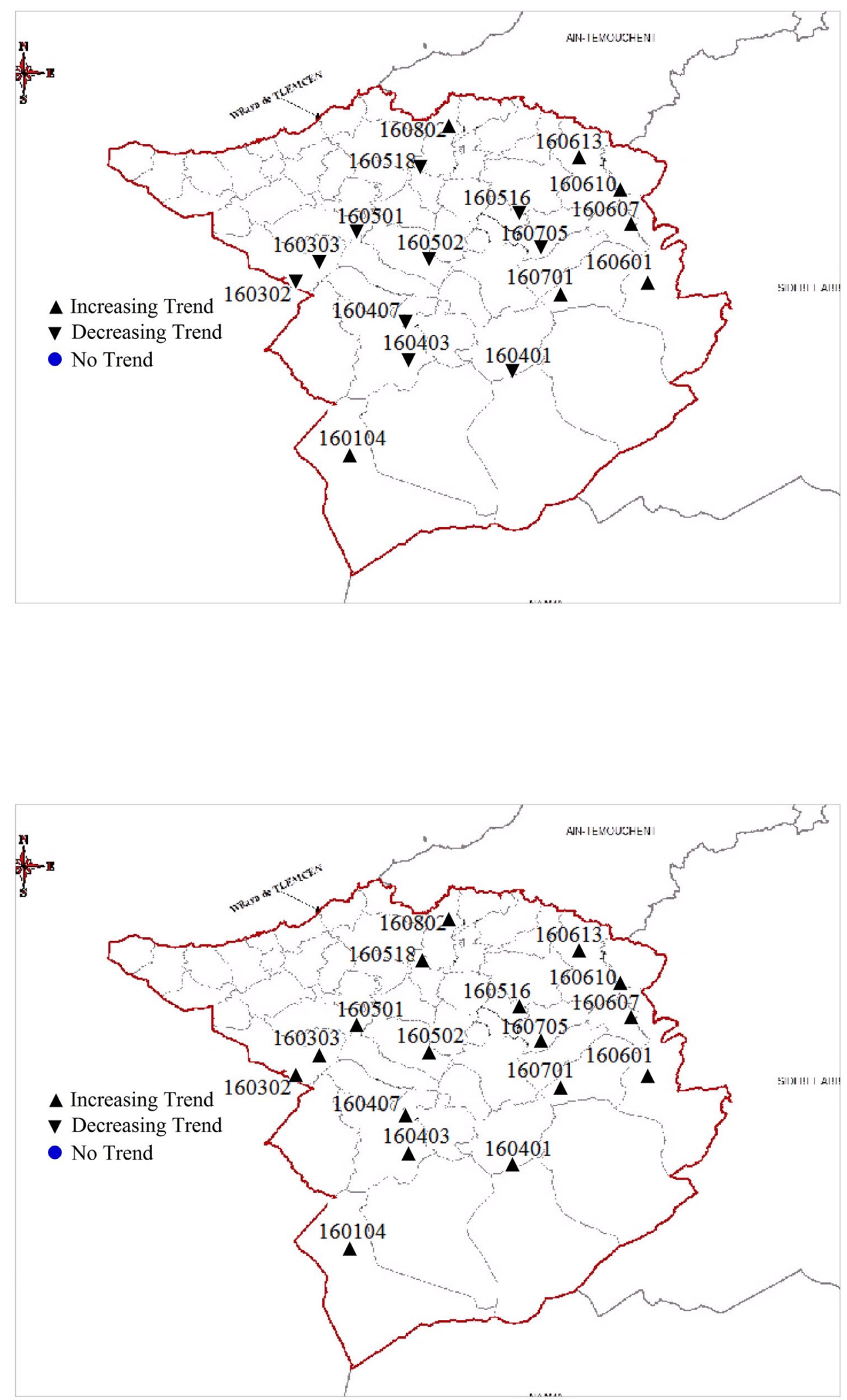
Fig. 18 Spatial trend partition of the Tafna watershed area (February month)
Fig. 19 Spatial trend partition of the Tafna watershed area (March month)
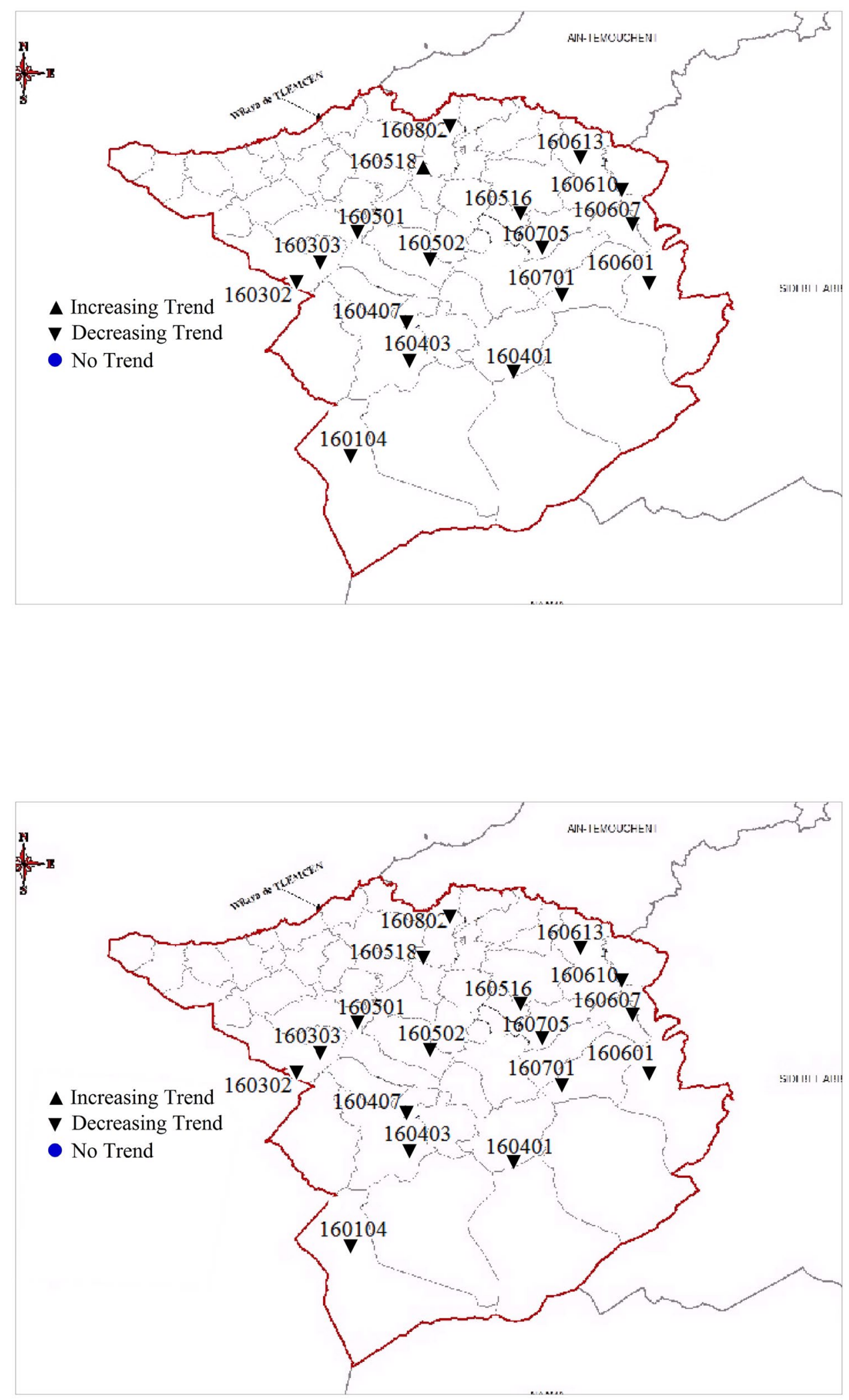
Fig. 20 Spatial trend partition of the Tafna watershed area (April month)
Fig. 21 Spatial trend partition of the Tafna watershed area (May month)
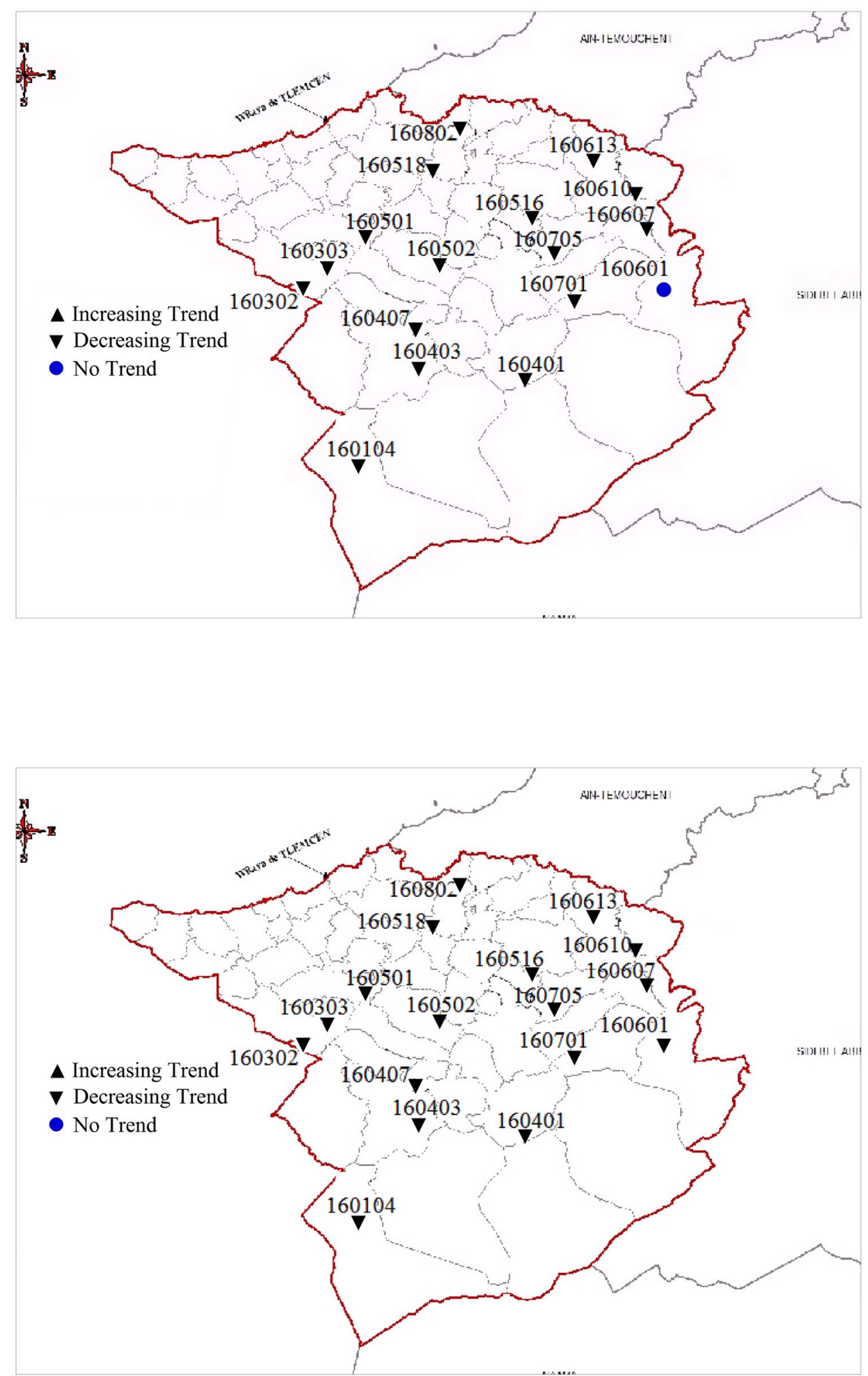
Fig. 22 Spatial trend partition of the Tafna watershed area (June month)
Fig. 23 Spatial trend partition of the Tafna watershed area (July month)
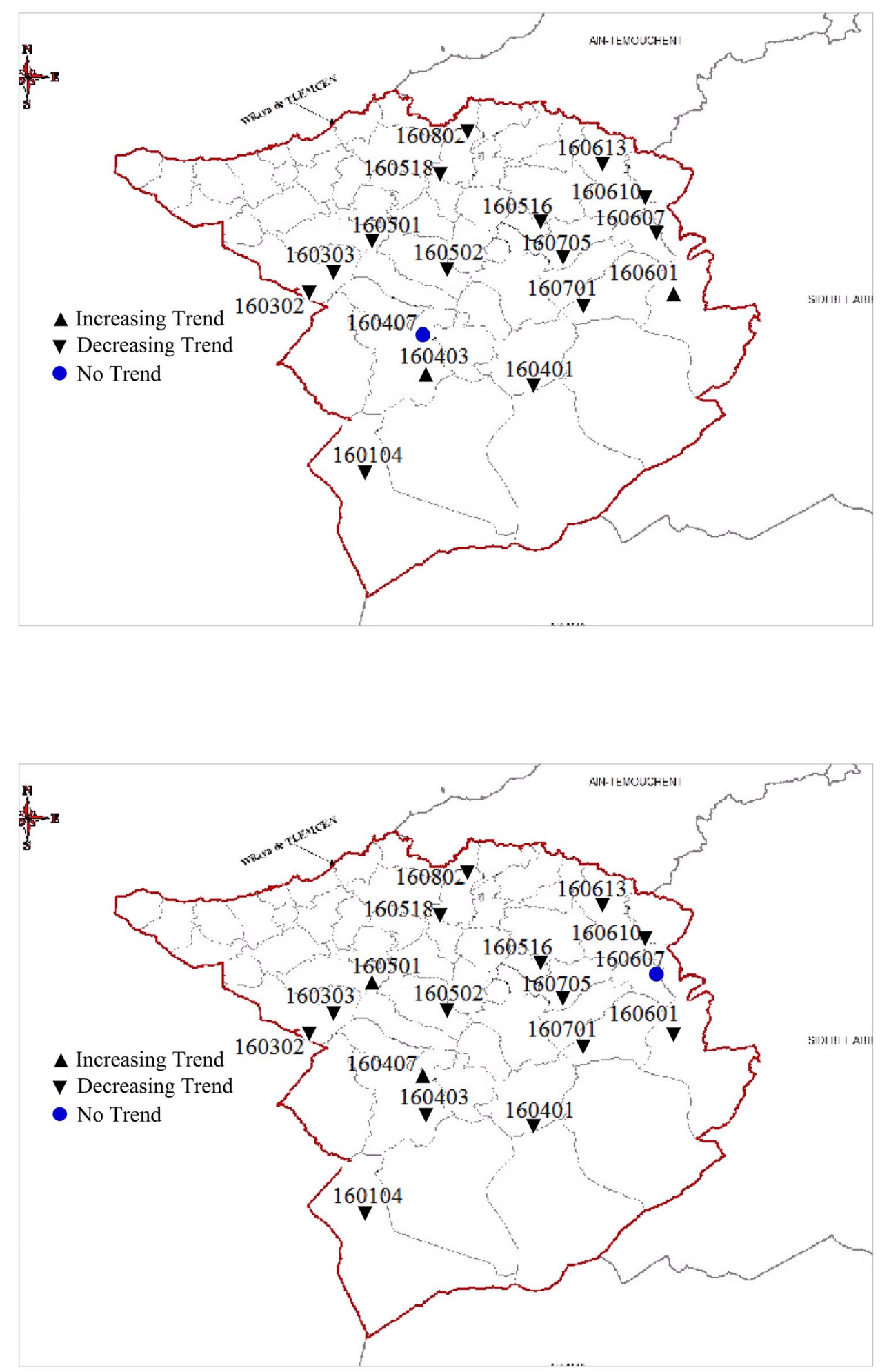
Fig. 24 Spatial trend partition of the Tafna watershed area (August month)

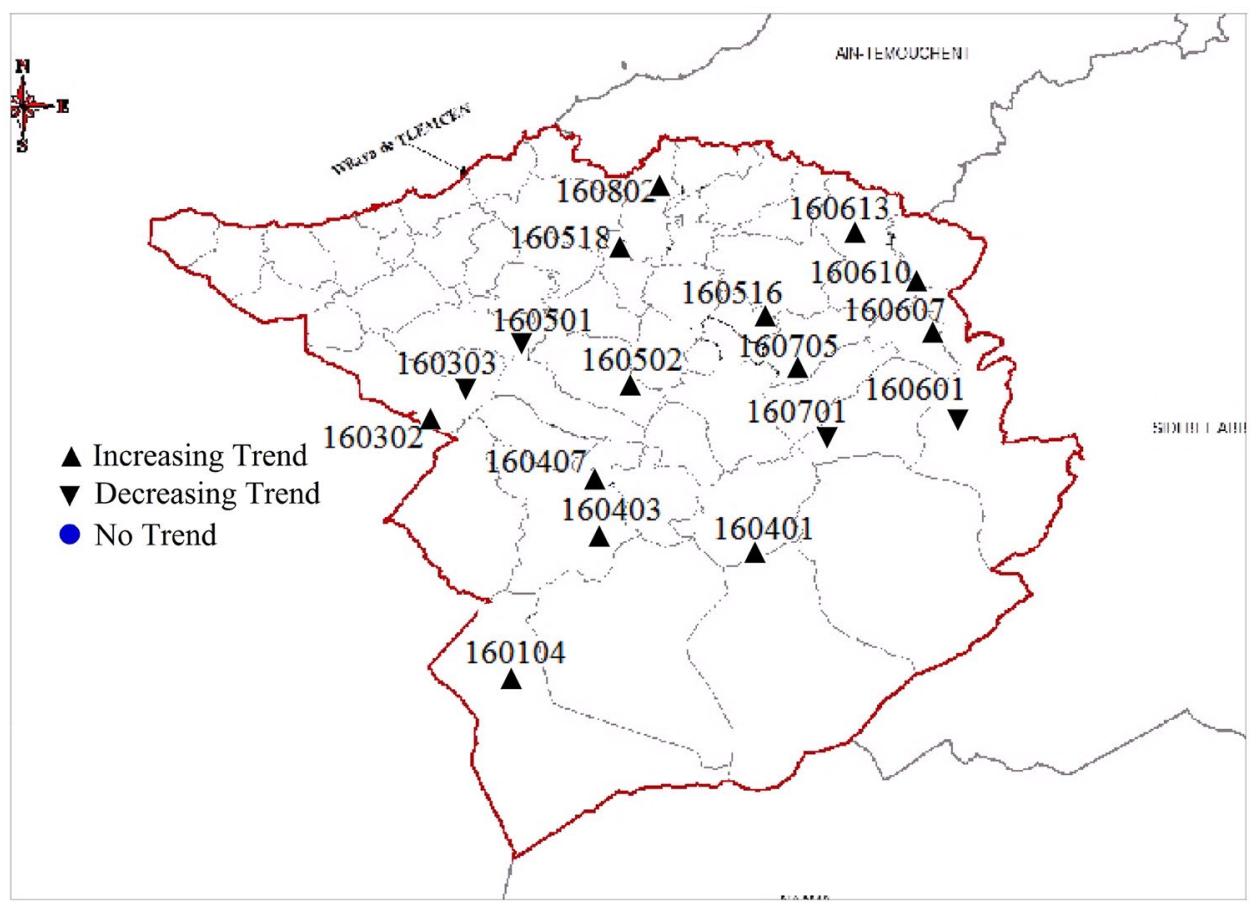

Acknowledgements Authors thank National Agency for Water Resources (ANRH) for providing the observed precipitation data. We extend our gratitude to Pr. Laborde J. for his free Hydrolab software used for data analysis.

Funding "The authors received no specific funding for this work.

\section{Declarations}

Conflict of interest The authors declare that they have no conflict of interest.

Open Access This article is licensed under a Creative Commons Attribution 4.0 International License, which permits use, sharing, adaptation, distribution and reproduction in any medium or format, as long as you give appropriate credit to the original author(s) and the source, provide a link to the Creative Commons licence, and indicate if changes were made. The images or other third party material in this article are included in the article's Creative Commons licence, unless indicated otherwise in a credit line to the material. If material is not included in the article's Creative Commons licence and your intended use is not permitted by statutory regulation or exceeds the permitted use, you will need to obtain permission directly from the copyright holder. To view a copy of this licence, visit http://creativecommons.org/licenses/by/4.0/.

\section{References}

Aboura R (2006) Comparaison Phyto-Ecologique Des Atriplexales Situées Au Nord Et Au Sud De Tlemcen Université De Abou Bekr Belkaid Tlemcen Thèse De Magistère

Bouklikha A, Habi M, Elouissi A, Benzater B, Hamoudi S (2020) The innovative trend analysis applied to annual and seasonal rainfall in the Tafna Watershed (Algeria). Rev Bras Meteorol 35(4):631-647. https://doi.org/10.1590/0102-77863540068

Dabanli I, Şen E, Yeleğen MÖ, Şisman E, Selek B, Güçlü YS (2016) Trend assessment by the innovative-Şen method. Water Resour Manage. https://doi.org/10.1007/s11269-016-1478-4

Elmeddahi Y (2016) Les Changements Climatiques Et Leurs Impacts Sur Les Ressources En Eau Université Hassiba Benbouali Chlef Cas Du Bassin Du Cheliff. Thèse de Doctorat

Elouissi A, Şen Z, Habi M (2016) Algerian rainfall innovative trend analysis and its implications to Macta watershed. Arab J Geosci. https://doi.org/10.1007/s12517-016-2325-x

Elouissi A, Habi M, Benaricha B, Boualem SA (2017) Climate change impact on rainfall spatiotemporal variability (Macta watershed case, Algeria). Arab J Geosci. https://doi.org/10. 1007/s12517-017-3264-x

Esteban-Parra M, Rodrigo F, Castro Y (1998) Spatial and temporal patterns of precipitation in Spain for the period 1880-1992. Int J Climatol 18:1557-1574

Ghenim AN, Megnounif A (2016) Variability and trend of annual maximum daily rainfall in Northern Algeria. Int Geophys. https://doi. org/10.1155/2016/6820397

Ghenim AN, Megnounif A, Seddini A, Terfous A (2010) Fluctuations hydropluviométriques du bassin versant de l'Oued Tafna à Béni Bahdel (Nord-Ouest Algérien). Sécheresse 21(2):115-120

Ghenim AN, Megnounif A, Djelloul SMIR SM (2014) Evaluation des changements dans la pluviométrie du bassin versant de la Tafna (nord-ouest de l'Algérie). Accessed 20 Jan 2019

Goubanova K, Li L (2007) Extremes in temperature and precipitation around the Mediterranean basin in an ensemble of future climate scenario simulations. Glob Planet Change 57:27-42. https://doi. org/10.1016/jgloplacha200611012,2007

Hydrolab (2010) Excel macros developed by JP Laborde helped by N MOUHOUS University of Nice Sophia Antipolis and National center of scientific research 
Intergovernmental Panel on Climate Change (IPCC) (2007) Climate change 2007: the physical science basis contribution of working group I to the fourth assessment report of the intergovernmental panel on climate change. Cambridge Univ Press, New York

Intergovernmental Panel on Climate Change (IPCC) (2013) In: Stocker Dahe Qin TF, Plattner GK, Melinda MB, Tignor Simon K, Boschung AJ, Nauels A, Xia Y, Bex V, Midgley PM (eds) Working group I technical support unit, working group I contribution to the fifth assessment report of the intergovernmental panel on climate change (IPCC), Summary for Policymakers

Kisi O, Ay M (2013) Comparison of Mann-Kendall and innovative trend method for water quality parameters of the Kizilirmak River Turkey. J Hydrol 513(2014):362-375. https://doi.org/10. 1016/j.jhydrol.2014.03.005

Longobardi A, Villani P (2010) Trend analysis of annual and seasonal rainfall time series in the Mediterranean area. Int J Climatol 30:1538-1546. https://doi.org/10.1002/joc2001

Lopez-Bustins, JA (2007) The western Mediterranean oscillation and rainfall in the Catalan countries. $\mathrm{PhD}$ thesis. University de Barcelona Spain, 184p

López-Moreno JI, Vecente-Serrano SM, Angulo-Martinez M, Beguería S, Kenawy A (2010) Trends in daily precipitation on the northeastern Iberian Peninsula, 1955-2006. Int J Climatol 30:10261041. https://doi.org/10.1002/joc1945

Maplecroft (2014) Climate Change Vulnerability Index 2014 [28 July 2014]

Meddi H, Meddi M (2009) Variabilité des précipitations annuelles du Nord-Ouest de l'Algérie. Article de recherche Sécheresse 20(1):57-65. https://doi.org/10.1684/sec20090169

Meddi MM, Assani AA, Meddi H (2010) Temporal variability of annual rainfall in the Macta and Tafna catchments Northwestern Algeria. Water Resour Manage 24:3817-3833. https://doi.org/10. 1007/s11269-010-9635-7

Meddi M, Toumi S, Mehaiguene M (2013) Hydrological drought in Tafna Basin-Algeria. researchGate. https://doi.org/10.13140/ 2125982245

Mekis E, Hogg WD (1999) Rehabilitation and analysis of Canadian daily precipitation time series. Atmos Ocean 37(1):53-85. https:// doi.org/10.1080/0705590019999649621

Merabti A, Meddi M, Martins DS, Pereira LS (2017) Comparing SPI and RDI applied at local scale as influenced by climate. Water Resour Manage. https://doi.org/10.1007/s11269-017-1855-7

Mohorji AM, Sen Z, Almazroui M (2017) Trend analyses revision and global monthly temperature innovative multi-duration analysis. Earth Syst Environ 1:9. https://doi.org/10.1007/ s41748-017-0014-x
Nichane M, Khelil MA (2015) Changements Climatiques Et Ressources En Eau En Algérie Vulnérabilité, Impact Et Stratégie D'adaptation. Larhyss J. ISSN 1112-3680, no 21 Mars 2015, pp 25-33

Öztopal A, Şen Z (2016) Innovative trend methodology applications to precipitation records in Turkey. Water Resour Manage. https://doi.org/10.1007/s11269-016-1343-5

Salameh T (2008) Modélisation multi-échelles de la circulation atmosphérique hivernale sur le bassin méditerranéen : rôle des interactions d'échelles Thèse de Doctorat. École polytechnique France, $11 \mathrm{p}$

Sayemuzzaman M, Manoj KJ (2013) Seasonal and annual precipitation time series trend analysis in North Carolina, United States. Atmos Res 137:183-194. https://doi.org/10.1016/jatmosres2 01310012

Şen Z (2012) Innovative trend analysis methodology. J Hydrol Eng 17(9):1042-1046

Şen Z (2014) Trend identification simulation and application. J Hydrol Eng 19(3):635-642

Taibi S, Meddi M, Souag D, Mahe G (2013) Evolution et régionalisation des précipitations au nord de l'Algérie (1936-2009). Climate and Land Surface Changes in Hydrology. In: Proceedings of H01, IAHS-IAPSO-IASPEI Assembly, Gothenburg, Sweden, July 2013 (IAHS Publ 359, 2013). https://www.researchgate.net/ publication/273060403 Accessed 24 Nov 2018

Taibi S, Meddi M, Mahé G, Assani A (2014) Variability of annual and extreme rainfall over Northern Algeria and relationship with teleconnections patterns. In: Proceedings of the mediterranean meeting on "monitoring, modelling and early warning of extreme. Events triggered by heavy rainfalls" PON 01_01503-MED-FRIEND project. University of Calabria, Cosenza (Italy). https://www.researchgate.net/publication/ 272745426. Accessed 10 Feb 2019

Taleb A, Belaidi N, Sanchez-Perez JM, Vervier P, Sauvage S, Gagneur J (2008) The role of the hyporheic zone of a semi-arid gravel bed stream located downstream of a heavily polluted reservoir (Tafna wadi, Algeria). River Res Appl 24:183-196. https://doi.org/10.1002/rra.1039

Toggweiler JR, Key RM (2001) Thermohaline circulation In: Steele JH, Thorpe SA, Turekian KK (eds) Encyclopedia of ocean sciences, pp 2941-2947

Zettam A, Taleb A, Sauvage S, Boithias L, Sanchez-Perez N (2017) Modelling hydrology and sediment transport in a semi-arid and anthropized catchment using the swat model: the case of the Tafna River (Northwest Algeria). Water 9:216 